Canadian

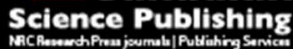

Canadian Geotechnical Journal Revue canadienne de géotechnique

\title{
Fatigue and damage properties of frozen silty sand samples subjected to cyclic triaxial loading
}

\begin{tabular}{|c|c|}
\hline Journal: & Canadian Geotechnical Journal \\
\hline Manuscript ID & cgj-2016-0152.R1 \\
\hline Manuscript Type: & Article \\
\hline Date Submitted by the Author: & 12-Jun-2016 \\
\hline Complete List of Authors: & $\begin{array}{l}\text { Liu, Enlong; State Key Laboratory of Frozen Soil Engineering, Cold and Arid } \\
\text { Regions Environmental and Engineering Research Institute, Chinese } \\
\text { Academy of Sciences, Lanzhou, 730000, China } \\
\text { Lai, Yuanming; Cold and Arid Regions Environmental Research Institute, } \\
\text { Chinese Academy of Sciences, State Key Laboratory of Frozen Soil } \\
\text { Engineering } \\
\text { Liao, Mengke; State Key Laboratory of Frozen Soil Engineering, Cold and } \\
\text { Arid Regions Environmental and Engineering Research Institute, Chinese } \\
\text { Academy of Sciences, Lanzhou, 730000, China } \\
\text { Liu, Xingyan; State Key Laboratory of Frozen Soil Engineering, Cold and } \\
\text { Arid Regions Environmental and Engineering Research Institute, Chinese } \\
\text { Academy of Sciences, Lanzhou, 730000, China } \\
\text { Hou, Feng; sichuan university, }\end{array}$ \\
\hline Keyword: & \\
\hline
\end{tabular}




\title{
Fatigue and damage properties of frozen silty sand samples subjected to
}

\author{
cyclic triaxial loading
}

\author{
Enlong Liu ${ }^{1,2}$, Yuanming Lai ${ }^{1}$, Mengke Liao ${ }^{1}$, Xingyan Liu ${ }^{1}$,Feng Hou $^{2}$ \\ 1 State Key Laboratory of Frozen Soil Engineering, Cold and Arid Region Environmental and Engineering Institute, Chinese \\ Academy of Sciences, Lanzhou, Gansu 730000, China; 2 State Key Laboratory of Hydraulics and Natural River Engineering, College \\ of Water Resource and Hydropower, Sichuan University, Chengdu, P.R. China 610065. Corresponding author: Yuanming Lai. \\ Contact Tel: +869314967024 and Email: liuenlong@1zb.ac.cn.
}

\begin{abstract}
Cyclic triaxial tests were conducted to explore the influences of dynamic axial loading on the dynamic features and fatigue of frozen silty sand. The apparatus employed was an MTS-810 material test system. The temperature was $-15^{\circ} \mathrm{C}$, and the cyclic axial loads with different amplitudes at $1.0 \mathrm{~Hz}$ were applied under confining pressures of 0.6, 1.4 and 6.0 MPa. The cyclic triaxial test results demonstrate that the residual axial strain of the frozen silty sand samples gradually increases during the initial cycles and then increases with increasing number of cycles at a constant speed until failure. The residual volumetric strain contracts during the initial loading cycles and then dilates until failure. Both the residual strain method and the residual volumetric strain method proposed here can be used to describe the degradation process in frozen silty sand samples subjected to cyclic loading. The dynamic axial stiffness of a frozen sample decreases rapidly in the initial cycles and then approaches a stable value with increasing cycle number. The initial damage increases when the stress ratio SR increases; the larger the stress ratio, the smaller the number of cycles at failure.
\end{abstract}

KEY WORDS: fatigue properties; cyclic triaxial tests; frozen silty sand; dynamic mechanical features

\section{INTRODUCTION}

Frozen soils are compound materials comprsing solid mineral particles, ice inclusions, liquid water (unfrozen water and tightly bound water) and gaseous inclusions (water vapor and air), whose mechanical and deformation characteristics are very distinct from other geological materials, such as soils, concrete and rocks at room temperature (Tsytovich 1985; Andersland et al. 2004). When subjected to seismic loading, frozen soils may deform permanently and gradually degrade in stiffness or strength. These fatigue and damage properties of frozen soils will deeply affect the stability and safety of structures built on these seasonally frozen grounds (He et al. 1993; Zhu et al. 2011; Li et al. 2012). There are approximately 2.15 
million $\mathrm{km}^{2}$ of permafrost region and 5.14 million $\mathrm{km}^{2}$ of seasonally frozen regions that are distributed in Western and Northern China (Zhou et al. 2000). With the increased amount of railways and oil line consruction in seismic areas with seasonally frozen soils, studies of the mechanical properties of frozen soils subjected to cyclic or fatigue loading have become increasingly important and represent a popular topic ingeotechnical engineering (Watson et al. 1973; Jiao et al. 2010).

The dynamic and fatigue properties of unfrozen soils have been investigated under cyclic or repeated loading conditions in detail and can be used to solve many problems in practical engineering (Ishihara 1996; Seed et al. 1983). However, frozen soil dynamics are still in the initial stage of development (Vinson et al. 1978; Simonsen et al. 2002). Several studies on these types of soils have been performed and are required for engineering practice in cold and seismic regions. They mainly include theoretical and experimental studies (Lai et al. 2000). Based on the research methods of unfrozen soils, many researchers have conducted in situ measurements of wave speed, laboratory tests of triaxial dynamic loading, resonantcolumn tests and wave speed studies to explore the differences in dynamic parameters between unfrozen soils and frozen soils (Ma and Wang 2014). For example, Li et al. (1979) employed a MTS electrohydraulic closed-loop testing system to perform strain-controlled cyclic tests on ice-saturated samples, demonstrating that the dynamic Young's modulus increased with increasing frequency, confining pressure and sand content but decreased with increasing strain and temperature. Additionally, the damping ratio decreases with increasing frequency and sand content and decreasing temperature. AI-Hunaidi et al. (1996) investigated the dynamic shear moduli and damping ratios of frozen soil samples using the resonantcolumn test method. The test results showed that the damping ratio of the frozen soil specimens was nearly twice that of the unfrozen specimens at low-amplitude shear strains. However, the dynamic shear moduli of the frozen specimens are significantly greater than those of the unfrozen specimens. Ling et al. (2009) studied the effects of temperature, water content and confining pressure on the dynamic elastic modulus ratio. The stress-strain curves of frozen soils were obtained using a dynamic triaxial apparatus, and the stiffness and the damping ratio evolutions of frozen clays under long-term and low-level repeated cyclic loading were also investigated by establishing stiffness and damping ratio evolution models (Ling et al. 2013). They also explored the dynamic shear modulus and damping ratio of a frozen compacted sand subjected to a freeze-thaw cycle under multi-stage cyclic loading (Ling et al. 2015). Zhang et al. (2011) 
performed a series of tests on frozen specimens, with temperature monitored using an embedded thermistor temperature sensor during cyclic compressive loading. Additionally, they investigated the influences of stress amplitude, frequency and water content on temperature change. Zhao et al. (2014) employed a largescale multi-functional direct shear apparatus (DDJ-1) to measure and analyze the cyclic shear properties of an artificially frozen soil-structure interface and found that the maximum shear stress is significantly affected by both the frozen soil temperature and initial normal stress. The relationship between peak shear stress and normal stress still follows the Mohr-Coulomb law. These studies of frozen soils subjected to cyclic loading focused on the dynamic ratio, stiffness evolution and their associated factors. In addition to frozen soils, Li et al. (2003) studied the fatigue features of frozen sandstone samples in cracked and saturated states, finding that compared with the non-cracked and frozen sandstone samples, the cracked and frozen samples had more obvious fatigue effects. Under repeated or cyclic loading, the frozen samples may become fatigued and gradually become damaged until failure occurs due to unacceptable deformation $(\mathrm{Xu}$ et al. 2015). Although some studies have been performed on the dynamic mechanical features of frozen soils, few studies have focused on the fatigue and damage properties of frozen soil samples subjected to cyclic loading. Therefore, we will investigate the fatigue and damage features of frozen silty sand samples subject to triaxial cyclic loading, which can deepen the understanding of their dynamic features in seismic areas covered by these seasonal frozen soils.

In this study, the frozen silty sand samples were subjected to axial cyclic loading at a frequency of 1.0 $\mathrm{Hz}$ to experimentally explore their fatigue and damage mechanical properties. The frozen silty sand samples at confining pressures of $0.6,1.4$ and $6.0 \mathrm{MPa}$ with different axial cyclic loads were analyzed at $15^{\circ} \mathrm{C}$. Finally, their dynamic properties and fatigue characteristics under triaxial cyclic loading were comprehensively analyzed.

\section{EQUIPMENT AND TEST SCHEME}

The soils tested were silty sands extracted from cold areas on the Qinghai-Tibet Plateau. Its grade curve is shown in Fig. 1, and its natural water content is $8.86 \%$, plastic limit $w_{\mathrm{P}}$ is $18.30 \%$ and liquid limit $w_{\mathrm{L}}$ is $32.3 \%$. The silty sands were sieved through a $0.5 \mathrm{~mm}$ screen and prepared with a water content of $15.46 \%$ to create the frozen samples. The samples were prepared according to the Specification of Soil Tests 
(GB/T50123-1999) issued by the Ministry of Water Resources, PRC. The following steps are used to form the frozen silty sand samples: (i) the prepared silty sands were placed in a cylindrical steel model with an inner diameter of $61.8 \mathrm{~mm}$ to form samples with a dry density of $1.848 \mathrm{~g} / \mathrm{cm}^{3}$, a diameter of $61.8 \mathrm{~mm}$ and a height of $125 \mathrm{~mm}$ by applying approximately $8 \mathrm{kN}$ vertical loads at a suitable speed using the samplemaking machine. During this process, some lubricating oil was smeared on the inner surface of the mold to reduce the friction between the sample and the inner surface of the mold; (ii) the formed samples were placed in another mold with three of the same parts and saturated under a vacuum for 3 hours; (iii) at the end of saturation, the molds enclosing the samples were placed in a refrigeration unit and were frozen quickly at a temperature of $-30{ }^{\circ} \mathrm{C}$ to avoid frost heave and prevent moisture transmission; (iv) after a freezing duration of 48 hours, the molds were removed and the samples were mounted with epoxy resin plates on both end surfaces and covered with a rubber sleeve to avoid moisture evaporation; and (v) the samples were placed in an incubator for over 24 hours at the test target temperature of $-15^{\circ} \mathrm{C}$ to ensure that the samples reached a uniform test temperature.

A cryogenic triaxial apparatus, as shown in Fig. 2, which was modified from the MTS-810 material test machine at the State Key Laboratory of Frozen Soil Engineering in Lanzhou, was employed here to perform the cyclic loading tests on the frozen silty sand samples. The cryogenic triaxial apparatus consisted of hardware components and software applications that provided closed-loop control of the servo-hydraulic test equipment, including the following four parts: a compression loading frame, an axial dynamic loading system, a cryogenic controlling component and a data acquisition system. A detailed description of this apparatus was provided by Zhang et al. (2011). The temperature error was smaller than $0.1{ }^{\circ} \mathrm{C}$, and the frequency could be changed from 0 to $50 \mathrm{~Hz}$.

The temperature in the pressure chamber was set at $-15{ }^{\circ} \mathrm{C}$ with a precision of $\pm 0.1{ }^{\circ} \mathrm{C}$. Then, the prepared samples were consolidated under preset pressures of $0.6,1.4$, and $6.0 \mathrm{MPa}$ for 2 hours prior to the axial static or dynamic load. For the dynamic test, the axial dynamic load was specified as a sinusoidal cyclic compressive load, and three to four sets of axial dynamic loads were applied. The initial void ratio of the frozen samples tested was 0.606 . The loading frequency was set to $1.0 \mathrm{~Hz}$, and the load path employed is schematically illustrated in Fig. 3. Failure was defined as the sum of the elastic strain and plastic strain, 
and it equals 15\% (Ling et al. 2015). The samples tested are summarized in Table 1. For the static tests, the axial loading rate was $1.08 \mathrm{~mm} / \mathrm{min}$, and the loads were applied with an axial displacement control.

\section{EXPERIMENTAL RESULTS}

\section{Static Triaxial Compressive Tests}

Static triaxial tests were performed to provide the mechanical parameters for the frozen silty sand samples. Fig. 4 presents the curves of the deviatoric stress-axial strain and volumetric strain-axial strain for samples of S0.6, S1.4 and S6.0 at confining pressures of 0.6, 1.4 and $6.0 \mathrm{MPa}$, respectively, where the compressive stress positive and compressive strain are both positive. All the samples exhibit strain hardening and reach stable values of deviatoric stress at larger axial strains. With increased confining pressure, the deviatoric stress reaches the largest value at a confining pressure of $1.4 \mathrm{MPa}$ and then decreases, reflecting the influence of confining pressure on the strength of the frozen samples. Within the small axial strain range, all the samples exhibit volumetric contraction and reach peak values, followed by dilatancy with increasing axial strain. Fig. $4 \mathrm{~b}$ shows that the lower the confining pressure, the larger the volumetric contraction. The volumetric strain at the beginning of deviatoric stress loading is the main effect of the whole loading process. For the samples tested at a confining pressure of $0.6 \mathrm{MPa}$, the volumetric strain at the beginning of deviatoric stress loading is $11.17 \%$. For the sample tested at a confining pressure of $6.0 \mathrm{MPa}$, the volumetric strain at the beginning of deviatoric stress loading is $15.20 \%$. Thus, the higher the confining pressure, the more the volume contracts at the beginning of deviatoric stress loading. Compared with the volumetric strain that occurs at the beginning of deviatoric stress loading, the volumetric strain induced in the process of deviatoric stress loading is very small. Because larger volumetric strain is induced at the beginning of deviatoric stress loading at a higher confining pressure, a smaller volumetric strain will occur within the small axial strain range will occur compared with those of samples tested at lower confining pressures, with small differences in the deviatoric stress, as shown in Fig. 4a. At failure, the test results demonstrate that all the samples dilate.

\section{Cyclic Dynamic Tests}

In the cyclic dynamic tests loaded along the stress path shown in Fig. 3, the dynamic stress and dynamic strain were recorded in the process of applying cyclic deviatoric stress at confining pressures of $0.6,1.4$ and 
6.0 MPa. Some test results are shown in Fig. 5 through Fig. 10, in which the axial cyclic loads vary from the largest (or peak) value to the smallest value (or valley) in a cycle. The following conclusions can be drawn from the experimental results: (i) during the process of cyclic loading, the frozen silty sand samples exhibit elasto-plastic behavior; with increasing numbers of cycles, the plastic or irreversible strain becomes larger; (ii) with increasing maximal dynamic axial load, both the number of cycles at failure and the values of the maximal volumetric contraction at the beginning of axial deviatoric stress unloading decrease at the same confining pressure; and (iii) with the increase in the axial strain or number of cycles, the differences in the residual strains, including the residual axial and volumetric strains, between two adjacent cycles decrease in all of the samples tested. The reason for this can be explained as follows. In the initial cycles, the frozen silty sand samples contract and the samples become more difficult to contract under undrained conditions as the number of cycles increases. For the frozen silty sand samples, the ice inclusions can contract, and the breakage (or damage) and slippage along the interfaces between ice inclusions and soil particles can lead to plastic deformation. With increased cyclic loading, more microfractures and slippage along the interfaces can occur, the plastic strain becomes larger and the differences in residual strains including residual axial and volumetric strains, between two adjacent cycles decrease.

\section{Residual Strain of Cyclic Tests}

The residual strain is defined as the strain (including axial and volumetric strains) at which the axial load reaches the minimal value in a cycle after $N$ cycles (Liu et al. 2012). Figs. 11 a through $\mathrm{j}$ present the relationship curves of the residual strain and the number of cycles $(N)$ for samples D0.6-1, D0.6-2, D0.6-3, D0.6-4, D1.4-1, D1.4-2, D1.4-3, D6.0-1, D6.0-2 and D6.0-3, respectively. For all the samples, the residual axial strain exhibits a similar evolution with increasing number of cycles. As demonstrated in Fig. 11, as $N$ increases, the residual axial strain gradually increases during its initial cycles and then increases with a constant speed until failure. At the same confining pressure, the cycle number at failure decreases at a similar value of the residual axial strain with increasingmaximal dynamic axial load.

Figs. 12 a through i present the relationship curves of the residual volumetric strain and the number of cycles $(N)$ for samples D0.6-1, D0.6-2, D0.6-4, D1.4-1, D1.4-2, D1.4-3, D6.0-1 D6.0-2 and D6.0-3. For the samples tested at confining pressures of $0.6 \mathrm{MPa}$ and 1.4 MPa, the residual volumetric strain contracts during the initial loading cycles and then dilates until failure. For the samples tested at a confining pressure 
of 6.0 $\mathrm{MPa}$, the residual volumetric strain dilates during the whole process of dynamic loading, and with the increase in cycle number, dilatancy also increases until failure. Because of the smaller deviatoric dynamic stress applied and a larger number of cycles for sample D6.0-3, its residual volumetric strain is smaller and fluctuates slightly. According to the development of the residual volumetric strain and its increasing speed, the residual volumetric strains of frozen silty sand samples obtained at a confining stress state, as shown in Figs. 12 a through i, can be described as three types of deformational curves as shown in Fig. 13. Type A includes Stage I, Stage II and Stage III, and Type B and Type C only include Stage II and Stage III. Although both Type B and Type C include Stage II and Stage III, the residual volumetric strain of Type B in the initial cycles is dilative, that of Type $\mathrm{C}$ in the initial cycles is compressive. Stage I denotes the initial phase in which the residual volumetric strain first increases and gradually approaches a constant speed. Stage II denotes the uniform speed phase in which the residual volumetric strain increases at a constant speed. Stage III denotes the accelerated phase in which the residual volumetric strain increases rapidly with increasing speed until failure. The samples tested at a $0.6 \mathrm{MPa}$ confining pressure behave as Type A, those samples tested at a 1.4 MPa confining pressure behave as Type B, and those samples tested at a 6.0 MPa confining pressure behave as Type $\mathrm{C}$. The residual volumetric strain increases rapidly during the initial phase. After several cycles, the rate of residual volumetric strain development tends to stablilize. Near failure, the residual volumetric strain increases rapidly again to eventual failure. The frozen silty sand samples tested exhibit some or all of these deformation mechanisms upon dynamic loading, based on the loading conditions such as confining pressure or the maximal dynamic axial load.

\section{The Degradation of Dynamic Axial Stiffness}

With increasing loading cycles, the mechanical properties of frozen silty sand samples will degrade. One of these properties is the dynamic axial stiffness $A_{\text {sd }}$, which is defined as follows (Liu et al. 2011):

$$
A_{s d}=\Delta q_{N} / \Delta \varepsilon_{a, r e c}^{N}
$$

where $\Delta q_{N}$ is the axial deviatoric stress difference in a loading cycle in GPa and $\Delta \varepsilon_{a, \text { rec }}^{N}$ is the axial strain difference in a loading cycle obtained from the corresponding peak-valley data under cyclic dynamic conditions. 
Some results for the calculated dynamic axial stiffness using Eq. (1) are plotted against the cycle number, as shown in Fig. 14. The dynamic axial stiffness of the frozen samples decreases rapidly in initial cycles and stablilizes with increasing number of cycles. Upon cyclic loading, the dynamic loading causes more micro fractures to form, decreasing the stiffness. Within the initial cycles, the frozen samples have relatively few micro fractures, respresenting a larger stiffness. With the increasing number of cycles, the micro fractures grow in number gradually and may form weaker zones or planes in the samples, reducing the stiffness and becoming less stable. Although the cyclic dynamic loads and confining pressures are different, the stiffness values of frozen samples evolving similarly with increasing number of cycles.

\section{FATIGUE AND DAMAGE PROPERTIES}

Damage variables consider the influence of cyclic (or fatigue) loading and are one crucial when formulating fatigue theories for frozen soil samples. When fatigue and damage occur, many properties of solid materials including the elastic modulus, hardness, ultrasonic wave velocity and residual strength can decrease (Lemaitre 1996; Xiao et al.2010; Liu et al. 2012). The following damage variables are employed to explore the fatigue and damage evolution of frozen silty sand samples under triaxial cyclic loading conditions.

\section{$D$ Defined by the Residual Axial Strain Method}

The damage variable can be defined as the ratio of the residual axial strain after $N$ cycles $\varepsilon_{a, \text { res }}^{N}$ to the ultimate residual axial strain at failure $\varepsilon_{a, r e s}^{N_{f}}$ and expressed as follows:

$$
D=\varepsilon_{a, r e s}^{N} / \varepsilon_{a, r e s}^{N_{f}}
$$

where $N_{\mathrm{f}}$ is the number of cycles at failure (Xiao et al. 2010). Figs. 15 a through c present the evolution curves of $D$ with the number of cycles $N$ of the frozen silty sand samples tested at confining pressures of 0.6, 1.4 and 6.0 MPa. In all the samples subjected to dynamic axial loads, the resulting damage increases slowly in the initial cycles and becomes larger within subsequent cycles until failure. At the moment when the axially cyclic load is applied, the samples have initial damage, resulting from original defects and static confining pressures. Under the same confining pressure, the initial damage increases with increasing maximal dynamic axial loading. The damage variable $D$ defined by the residual axial strain method has a 
clear physical meaning and can consider both the initial damage and degradation process of frozen samples under triaxial cyclic loading conditions.

\section{$D$ Defined by the Residual Volumetric Strain Method}

The damage variable can also be defined by the residual volumetric strain as follows:

$$
D=\frac{\varepsilon_{V, \text { res }}^{i}-\varepsilon_{V, \text { res }}^{N}}{\varepsilon_{V, \text { res }}^{i}-\varepsilon_{V, \text { res }}^{F}},
$$

where $\varepsilon_{V, \text { res }}^{N}$ is the residual volumetric strain for the number of cycles $\mathrm{N}, \varepsilon_{V, \text { res }}^{i}$ is the residual volumetric strain in the first cycle, and $\varepsilon_{V, r e S}^{F}$ is the residual volumetric strain when failure occurs upon cyclic loading. In the definition given in equation (3), we pay more attention to the evolution of damage with the number of cycles and assume that the damage in the first cycle can be neglected. The damage evolution curves calculated using equation (3) are shown in Figs. 16 a through h, which present the three-stage (or two-stage) development process of fatigue damage at different confining pressures. With increasing number of cycles $N$, the damage $D$ increases to some magnitude and then becomes very large, with a rapidly increasing speed until the frozen sample fails. The damage $D$ expressed in equation (3) has a value ranging from 0.0 to 1.0 , which signifies the degradation process of frozen samples upon dynamic cyclic loading. Because the frozen samples can compress or dilate upon dynamic loading, the method proposed here is more reasonable when describing the damage evolution of frozen silty sand samples.

\section{The Effect of Stress Level on Damage Evolution}

The stress ratio SR is defined as follows:

$$
S R=\frac{q_{\text {max }, d y n}}{2 \tau_{s}}
$$

where $q_{\max , d y n}$ is the maximal deviatoric stress in a cycle. $\tau_{\mathrm{s}}=\left(\sigma_{1}-\sigma_{3}\right) / 2$, where $\sigma_{1}$ and $\sigma_{3}$ are the maximal principal stress and the minimal principal stress, respectively. $\sigma_{1}$ and $\sigma_{3}$ can be obtained for static triaxial loading at the same confining pressure as the axial dynamic conditions. Figs. $17 \mathrm{a}$ and $\mathrm{b}$ present the evolution of $S R$ with the initial fatigue damage obtained using the residual axial strain method and the number of cycles at failure, respectively, at $0.6,1.4$ and $6.0 \mathrm{MPa}$ confining pressures. The initial damage 
increases larger with the increasing stress ratio SR. Additionally, for the samples tested in a confining stress state, the larger the stress ratio, the smaller the number of cycles at failure.

\section{CONCLUSIONS}

From the cryogenic triaxial cyclic test results of frozen silty sand samples conducted at $0.6,1.4$, and 6.0 MPa confining pressures and $-15{ }^{\circ} \mathrm{C}$, some conclusions can be summarized as follows:

(1) With increasing numbers of cycles, the samples exhibit elastic-plastic and irreversible deformation, and the differences in the residual strains, including residual axial and volumetric strains between two adjacent cycles decrease in all of the samples tested. As $N$ increases, the residual axial strain of the frozen sample gradually increases during its initial cycles and then increases with a constant speed until failure. The residual volumetric strain contracts within the initial loading cycles and then dilates until the samples fail.

(2) The dynamic axial stiffness of a frozen sample decreases rapidly in the initial cycles and approaches a stable value as the cyclic number increases due to micro fracturing and a fatiguing phenomenon in the frozen silty sand sample.

(3) Both of the two damage variables including the residual axial strain method and the residual volumetric strain method, can be used to describe the degradation process in frozen silty sand samples subjected to cyclic loads. The first damage variable is more appropriate due to its distinct physical meaning and its ability to describe the initial fatigue damage. The second one has a value ranging from 0.0 to 1.0 and is more reasonable for describing the damage evolution process in frozen silty sand samples.

(4) The initial damage becomes larger with increasing stress ratio SR. Additionally, for samples tested at a confining stress state, the larger the stress ratio, the smaller the number of cycles at failure.

(5) With increasing confining pressure, the samples tested behave as Type A at a lower confining pressure of 0.6 MPa, as Type B at a 1.4 MPa confining pressure, and as Type $\mathrm{C}$ at a higher confining pressure of 6.0 $\mathrm{MPa}$, as shown in Fig. 13.

\section{ACKNOWLEDGMENTS}

The authors thank the two anonymous reviewers and Prof. Daichao Sheng for their careful review, contributions and critiques, which led to the improvement of the manuscript. The authors appreciate the funding provided by the CAS Pioneer Hundred Talents Program.

https://mc06.manuscriptcentral.com/cgj-pubs 


\section{REFERENCES}

AI-Hunaidi, M.O., Chen, P.A., Rainer, J.H. and Tremblay, M. 1996. Shear moduli and damping in frozen and unfrozen clay by resonant column tests. Canadian Geotechnical Journal, 33: 510-514.

Andersland, O.B., Ladanyi, B. 2004. Frozen ground engineering. John Wiley \& Sons: New Jersey.

He, P., Zhu, Y.L., Zhang, J.Y., Shen, Z.Y. and Yu, Q.H. 1993. Dynamic elastic modulus and dynamic strength of saturate frozen silts. Journal of Glaciology and Geocryology $15: 170-173$. (In Chinese).

Ishihara, K. 1996. Soil behaviour in earthquake geotechnics. Prentice Hall: New Jersey.

Jiao, G.D., Zhao, S.P., and Ma, W. 2010. Experimental study of the dynamic characteristics of warmfrozen silt after freeze-thaw cycle under cyclic loading. Chinese Civil Engineering Journal,43:107-113. (In Chinese).

Lai, Y.M, Wu, Z.W., Zhu, Y.L., and Zhu, L.N. 2000. Elastic visco-plastic analysis for earthquake response of tunnels in cold regions. Cold Regions Science and Technology, 31: 175-188.

Lemaitre, J. 1996. A course on damage mechanics. Springer: Berlin.

Li, J.C., Baladi, G.Y., and Andersland, O.B. 1979. Cyclic triaxial tests on frozen sand. Engineering Geology,13: 233-246.

Li, N., Zhang, P., Chen, W., and Swoboda, G. 2003. Fatigue properties of cracked, saturated and frozen sandstone samples under cyclic loading. International Journal of Rock Mechanics and Mining Science 40:145-150.

Li, S.Y., Lai, Y.M., Zhang, S.J., Yang, Y.G., and Yu, W.B. 2012. Dynamic response of Qinghai-Tibet railway embankment subjected to train loading in different seasons. Soil Dynamic and Earthquake Engineering, 32: 1-14.

Ling, X.Z, Zhu, Z.Y., Zhang, F., Chen, S.J., Wang, L.N., Gao, X., and Lu, Q.R. 2009. Dynamic elastic modulus for frozen soil from the embankment on Beiluhe Basin along the Qinghai-Tibet Railway. Cold Regions Science and Technology, 57: 7-12.

Ling, X.Z., Li, Q.L., Wang, L.N., Zhang, F., An, L.S., and Xu, P.J. 2013. Stiffness and damping ratio evolution of frozen clays under long-term low-level repeated cyclic loading: experimental evidence and evolution model. Cold Regions Science and Technology, 86: 45-54. 
Ling, X.Z., Zhang, F., Li, Q.L., An, L.S., and Wang, J.H. 2015. Dynamic shear modulus and damping ratio of frozen compacted sand subjected to freeze-thaw cycle under multi-stage cyclic loading. Soil Dynamic and Earthquake Engineering, 76: 111-121.

Liu, E., He, S., and Xue, X. 2011. Dynamic properties of intact rock samples subjected to cyclic loading under confining pressure conditions. Rock Mechanics and Rock Engineering, 44: 629-634.

Liu, E., and He, S. 2012. Effects of cyclic dynamic loading on the mechanical properties of intact rock samples under confining pressure conditions. Engineering Geology,125: 81-91.

Ma, W., and Wang, D.Y. 2014. Mechanics of frozen soils. Science Press: Beijing. (In Chinese).

Seed, H.B., Idriss, I.M., and Arango, I. 1983. Evalutaion of liquefaction potential using field performance data. Journal of Geotchncial Engineering, ASCE, 109: 458-482.

Simonsen, E., Janoo, V.C., and Isacsson, U. 2002. Resilient properties of unbound road materials during seasonal frost conditions. J. Cold Reg. Eng. 16(1): 28-50.

Vinson,T.S., Chaichanavong, T., and Czajkowski, R.L. 1978. Behavior of frozen clays under cyclic axial loading. J. Geotech. Eng. Div., 104(7): 779-800.

Watson, G.H., Slusarchuk, W.A., and Rowley, R.K. 1973. Determination of some frozen and thawed properties of permafrost soils. Can. Geotech. J. 10 (4): 592-606.

Xiao, J.Q., Ding, D.X., Jiang, F.L., and Xu, G. 2010. Fatigue damage variable and evolution of rock subjected to cyclic loading. International Journal of Rock Mechanics and Mining Science 47: 461-468.

Xu, X.T., Dong, Y.H. and Fan, C.X. 2015. Laboratory investigation on energy dissipation and damage characteristics of frozen loess during deformation process. Cold Regions Science and Technology, 109: $1-8$.

Tsytovich, N.A. 1985. The mechanics of frozen ground. Science Press: Beijing. Translated by Zhang, C.Q. and Zhu, Y.L.

Zhang, S.J., Lai, Y.M., Sun, Z.Z. and Chang, X.X. 2011. An experimental study of the heat generated during cyclic compressive loading of frozen soils. Cold Regions Science and Technology, 67: 165-170.

Zhao, L.Z., Yang, P., Wang, J.G., and Zhang, L.C. 2014. Cyclic direct shear behaviors of frozen soilstructure interface under constant normal stiffness condition. Cold Regions Science and Technology, 102: $52-62$. 
Zhou, Y.W., Guo, D.X., and Cheng, G.D. 2000. Frozen soil of China. Science Press: Beijing.

Zhu, Z.Y., Ling, X.Z., Chen, S.J., Zhang, F., Wang, Z.Y., Wang, L.N. and Zou, Z.Y. 2011. Analysis of dynamic compressive stress induced by passing trains in permafrost subgrade along Qing-Tibet Railway. Cold Regions Science and Technology, 65: 465-473. 


\section{Lists of Table and Figures}

Table 1. Summary of the samples tested

Figure 1. Grain size distribution curve of soil samples

Figure 2. The cryogenic cyclic triaxial test system

Figure 3. Load path: (a) typical stress path and (b) the loading sequence

Figure 4. Results of triaxial tests upon axial static loading: (a) Deviatoric stress-axial strain curve and (b) Volumetric strain-axial strain curve

Figure 5. Results of triaxial tests upon axial cyclic dynamic loading (Test No. D0.6-1): (a) Dynamic deviatoric stress-axial strain curve; and (b) Dynamic volumetric strain-axial strain curve

Figure 6. Results of triaxial tests upon axial cyclic dynamic loading (Test No. D0.6-4): (a) Dynamic deviatoric stress-axial strain curve; and (b) Dynamic volumetric strain-axial strain curve

Figure 7. Results of triaxial tests upon axial cyclic dynamic loading (Test No. D1.4-1): (a) Dynamic deviatoric stress-axial strain curve and (b) Dynamic volumetric strain-axial strain curve

Figure 8. Results of triaxial tests upon axial cyclic dynamic loading (Test No. D1.4-3): (a) Dynamic deviatoric stress-axial strain curve and (b) Dynamic volumetric strain-axial strain curve

Figure 9. Results of triaxial tests upon axial cyclic dynamic loading (Test No. D6.0-1): (a) Dynamic deviatoric stress-axial strain curve and (b) Dynamic volumetric strain-axial strain curve

Figure 10. Results of triaxial tests upon axial cyclic dynamic loading (Test No. D6.0-2): (a) Dynamic deviatoric stress-axial strain curve and (b) Dynamic volumetric strain-axial strain curve

Figure 11. Residual axial strain- $N$ curves ( $N$ : the number of cycles): (a) Test No. D0.6-1; (b) Test No. D0.62; (c) Test No. D0.6-3; (d) Test No. D0.6-4; (e) Test No. D1.4-1; (f) Test No. D1.4-2; (g) Test No. D1.43; (h) Test No. D6.0-1; (i) Test No. D6.0-2; and (j) Test No. D6.0-3

Figure 12. Residual volumetric strain- $N$ curves ( $N$ : the number of cycles): (a) Test No. D0.6-1; (b) Test No. D0.6-2; (c) Test No. D0.6-4; (d) Test No. D1.4-1; (e) Test No. D1.4-2; (f) Test No. D1.4-3; (g) Test No. D6.0-1; (h) Test No. D6.0-2 and (i) Test No. D6.0-3

Figure 13. Plot showing the three phases of residual axial strain ( $N$ : the number of cycles) 
Figure 14. Dynamic axial stiffness- Cycle Number $N$ curve: (a) $0.6 \mathrm{MPa}$ confining pressure; (b) $1.4 \mathrm{MPa}$ confining pressure; and (c) 6.0 MPa confining pressure

Figure 15. $D-N$ curves ( $N$ : the number of cycles) using the residual axial strain method: (a) $0.6 \mathrm{MPa}$ confining pressure; (b) 1.4 MPa confining pressure; and (c) 6.0 MPa confining pressure

Figure 16. $D$ - $N$ curves ( $N$ : the number of cycles) using the residual volumetric strain method: (a) Test No. D0.6-1; (b) Test No. D0.6-2; (c) Test No. D0.6-4; (d) Test No. D1.4-1; (e) Test No. D1.4-2; (f) Test No. D1.4-3; (g) Test No. D6.0-1; and (h) Test No. D6.0-2

Figure 17. Influence of SR on initial fatigue damage $D_{\mathrm{o}}$ and cycle number at failure $N_{\mathrm{f}}$ : (a) Curves of SR versus $D_{\mathrm{o}}$ and (b) Curves of SR versus $N_{\mathrm{f}}$ 
Table 1. Summary of the samples tested

\begin{tabular}{|c|c|c|c|}
\hline Test No. & $\begin{array}{l}\text { Confining } \\
\text { pressure(MPa) }\end{array}$ & Loading type & Loading condition \\
\hline S0.6 & 0.6 & Static & Triaxial, compression \\
\hline D0.6-1 & 0.6 & Cyclic, dynamic & $\begin{array}{l}\text { Triaxial, } 1 \mathrm{~Hz} \text {, axial dynamic loading:9-25kN, failed } \\
\text { after } 1101 \text { cycles }\end{array}$ \\
\hline D0.6-2 & 0.6 & Cyclic, dynamic & $\begin{array}{l}\text { Triaxial, } 1 \mathrm{~Hz} \text {, axial dynamic loading:9-24kN, failed } \\
\text { after } 2108 \text { cycles }\end{array}$ \\
\hline D0.6-3 & 0.6 & Cyclic, dynamic & $\begin{array}{l}\text { Triaxial, } 1 \mathrm{~Hz} \text {, axial dynamic loading:9-22kN, failed } \\
\text { after } 6475 \text { cycles }\end{array}$ \\
\hline D0.6-4 & 0.6 & Cyclic, dynamic & $\begin{array}{l}\text { Triaxial, } 1 \mathrm{~Hz} \text {, axial dynamic loading: } 1.2-25 \mathrm{kN} \text {, failed } \\
\text { after } 906 \text { cycles }\end{array}$ \\
\hline S1.4 & 1.4 & Static & Triaxial, compression \\
\hline D1.4-1 & 1.4 & Cyclic, dynamic & $\begin{array}{l}\text { Triaxial, } 1 \mathrm{~Hz} \text {, axial dynamic loading: } 9-29 \mathrm{kN} \text {, failed } \\
\text { after } 536 \text { cycles }\end{array}$ \\
\hline D1.4-2 & 1.4 & Cyclic, dynamic & $\begin{array}{l}\text { Triaxial, } 1 \mathrm{~Hz} \text {, axial dynamic loading:9-28kN, failed } \\
\text { after } 957 \text { cycles }\end{array}$ \\
\hline D1.4-3 & 1.4 & Cyclic, dynamic & $\begin{array}{l}\text { Triaxial, } 1 \mathrm{~Hz} \text {, axial dynamic loading: } 9-27 \mathrm{kN} \text {, failed } \\
\text { after } 1362 \text { cycles }\end{array}$ \\
\hline S6.0 & 6.0 & Static & Triaxial, compression \\
\hline D6.0-1 & 6.0 & Cyclic, dynamic & $\begin{array}{l}\text { Triaxial, } 1 \mathrm{~Hz} \text {, axial dynamic loading: } 23-43 \mathrm{kN} \text {, failed } \\
\text { after } 582 \text { cycles }\end{array}$ \\
\hline D6.0-2 & 6.0 & Cyclic, dynamic & $\begin{array}{l}\text { Triaxial, } 1 \mathrm{~Hz} \text {, axial dynamic loading: } 23-42 \mathrm{kN} \text {, failed } \\
\text { after } 919 \text { cycles }\end{array}$ \\
\hline D6.0-3 & 6.0 & Cyclic, dynamic & $\begin{array}{l}\text { Triaxial, } 1 \mathrm{~Hz} \text {, axial dynamic loading: } 23-40 \mathrm{kN} \text {, failed } \\
\text { after } 2534 \text { cycles }\end{array}$ \\
\hline
\end{tabular}




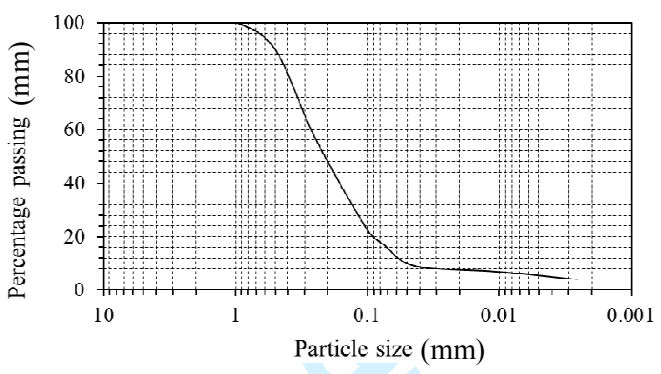

Fig.1. Grain size distribution curve of soil samples 


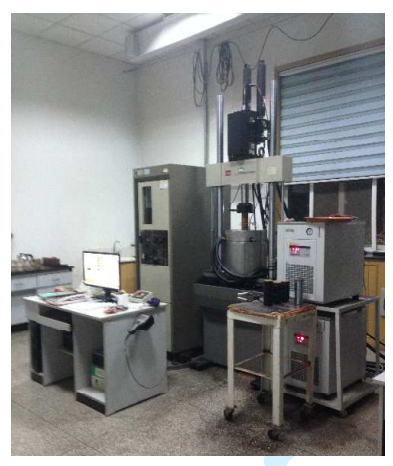

Fig. 2. The cryogenic cyclic triaxial test system 


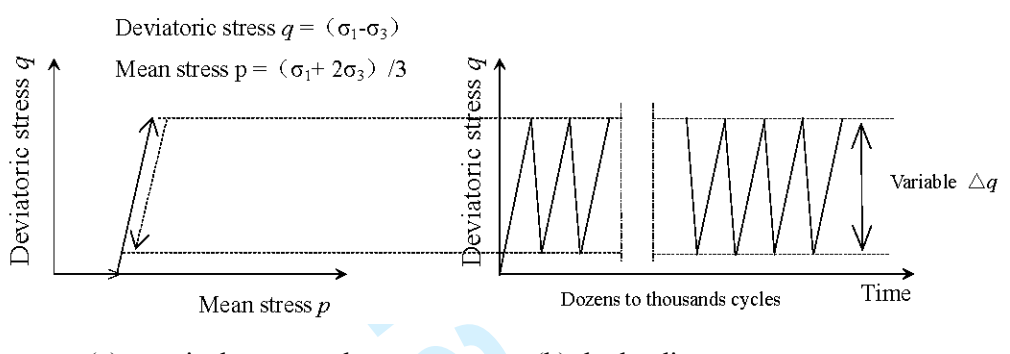

$\begin{array}{ll}\text { (a) a typical stress path } & \text { (b) the loading sequence }\end{array}$

Fig.3. Load path 


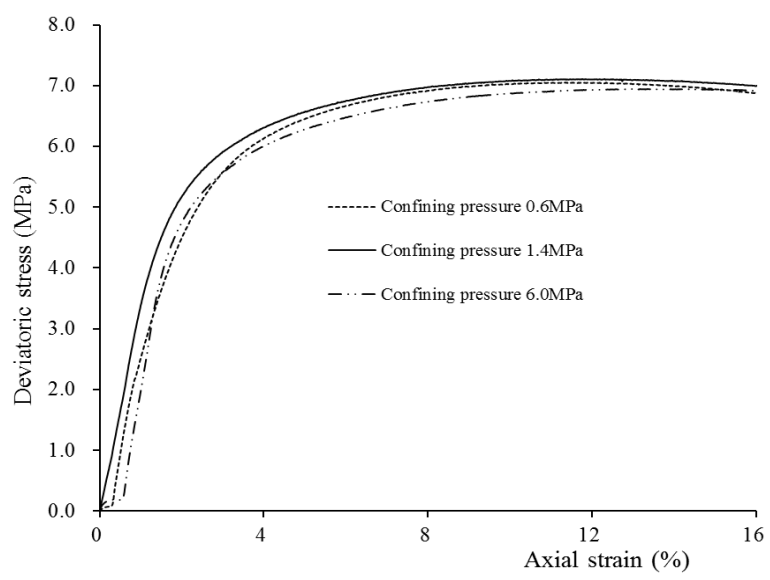

(a) Deviatoric stress-axial strain curve

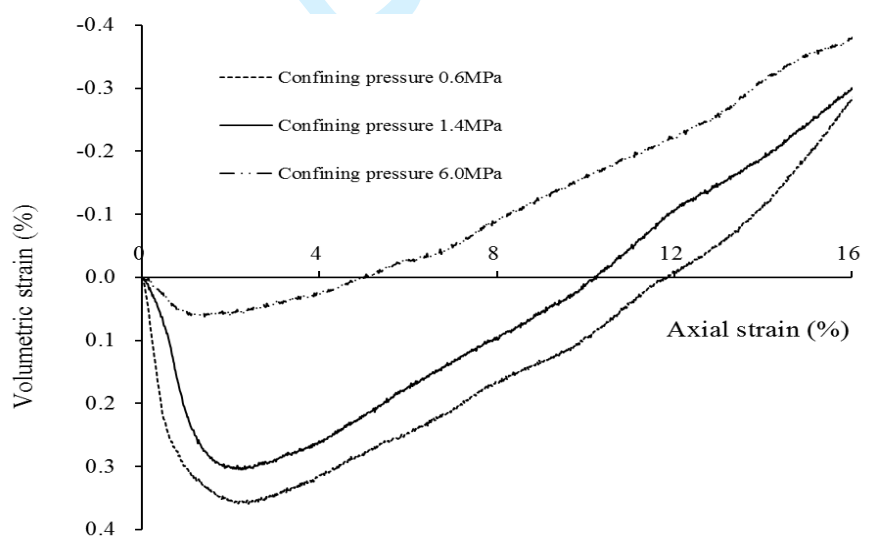

(b) Volumetric strain-axial strain curve

Fig. 4. Results of static triaxial tests 


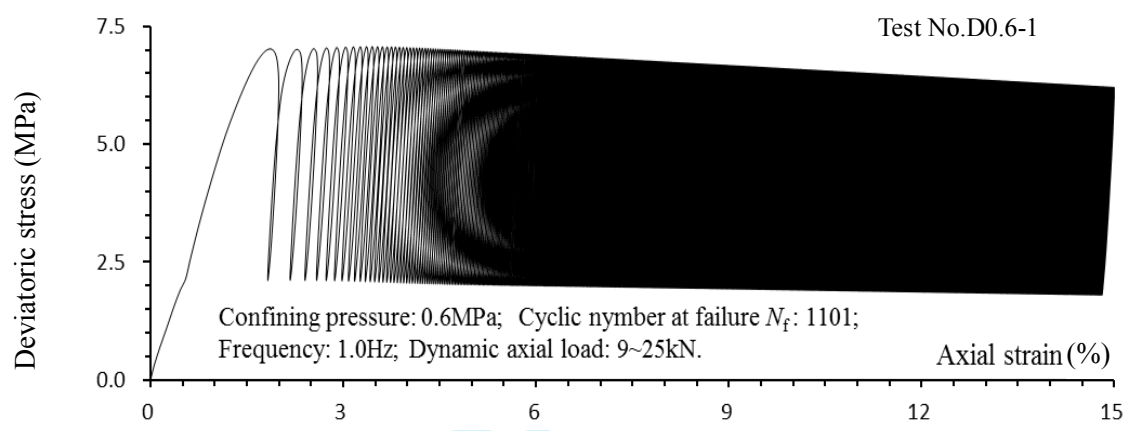

(a) Dynamic deviatoric stress-axial strain curve

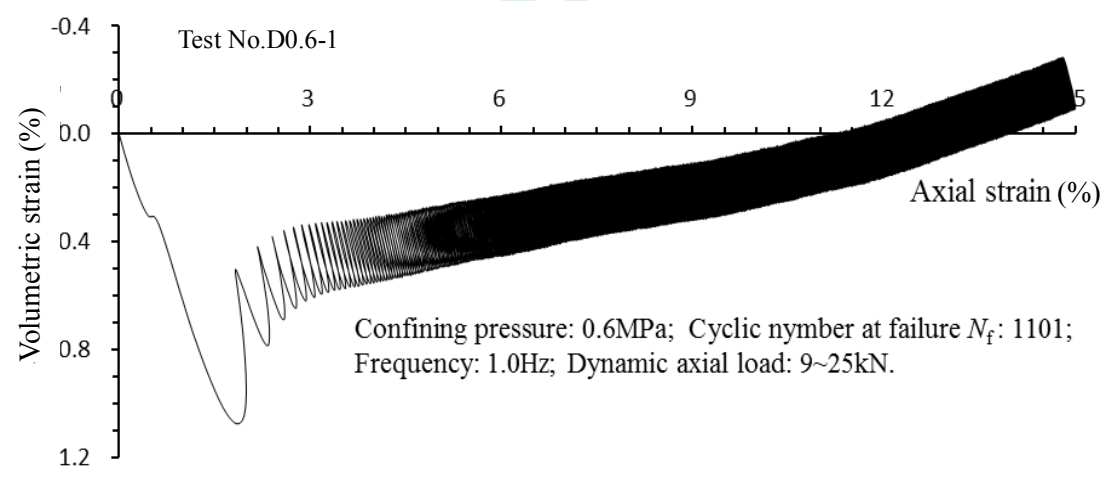

(b) Dynamic volumetric strain-axial strain curve

Fig. 5. Results of triaxial tests upon axial cyclic dynamic loading (Test No. D0.6-1) 


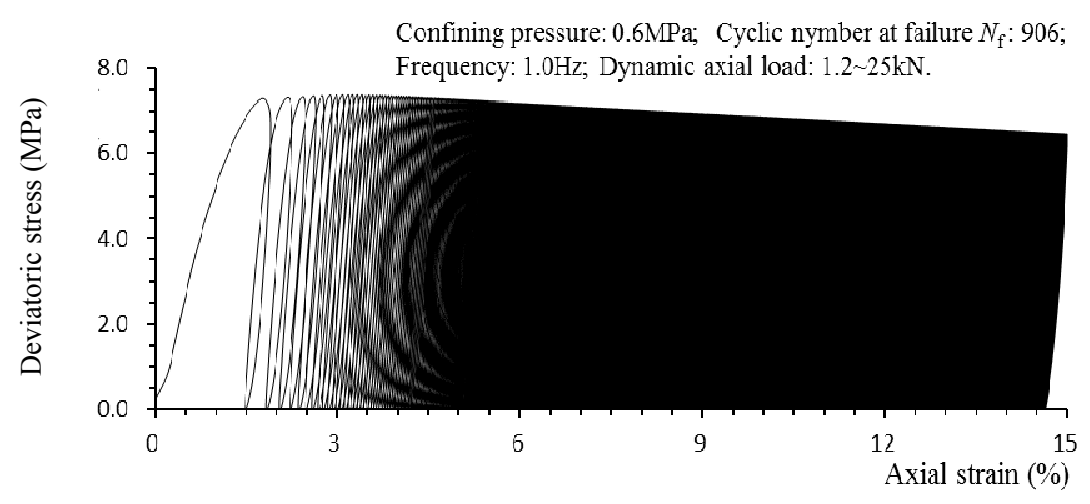

(a) Dynamic deviatoric stress-axial strain curve

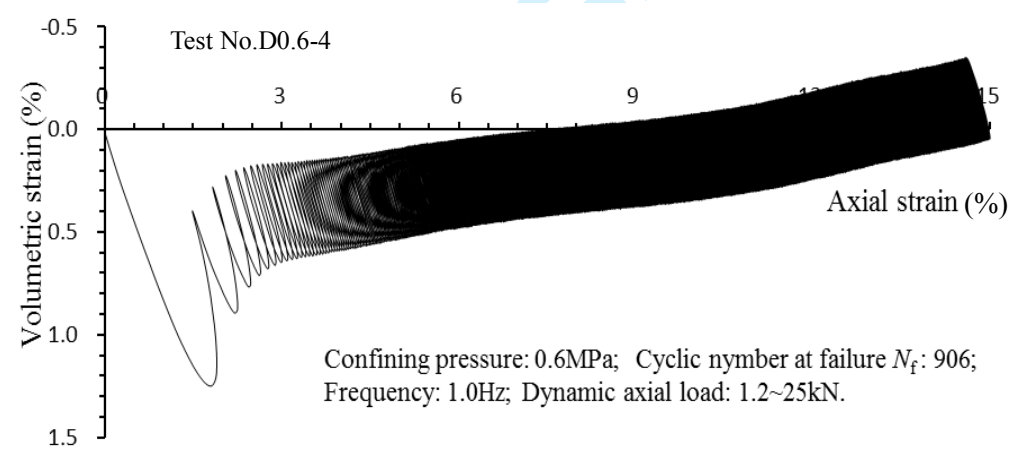

(b) Dynamic volumetric strain-axial strain curve

Fig. 6. Results of triaxial tests upon axial cyclic dynamic loading (D0.6-4) 


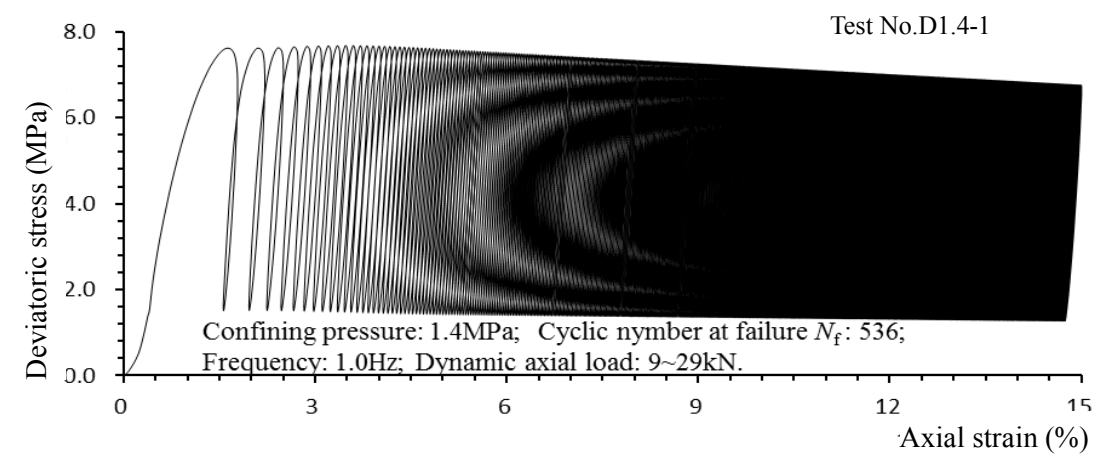

(a) Dynamic deviatoric stress-axial strain curve

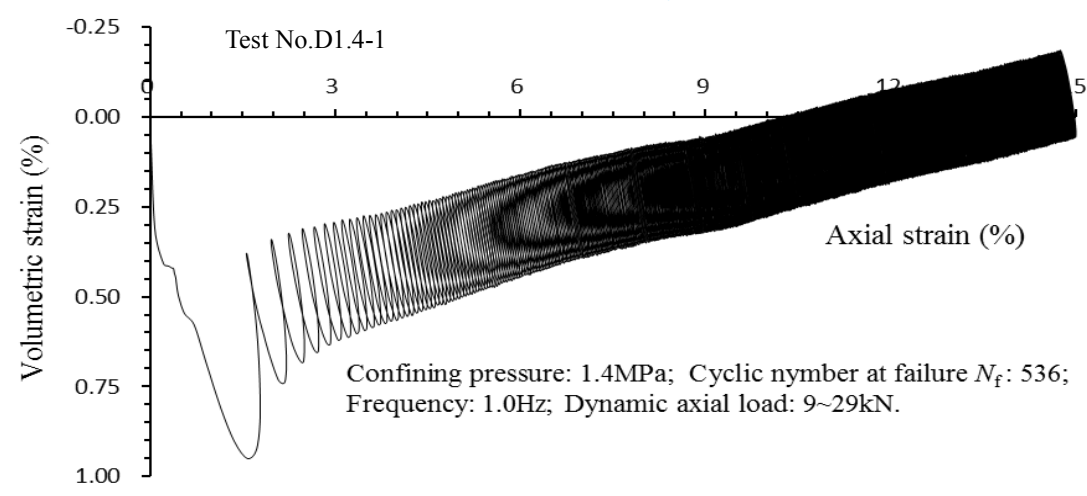

(b) Dynamic volumetric strain-axial strain curve

Fig. 7. Results of triaxial tests upon axial cyclic dynamic loading (D1.4-1) 


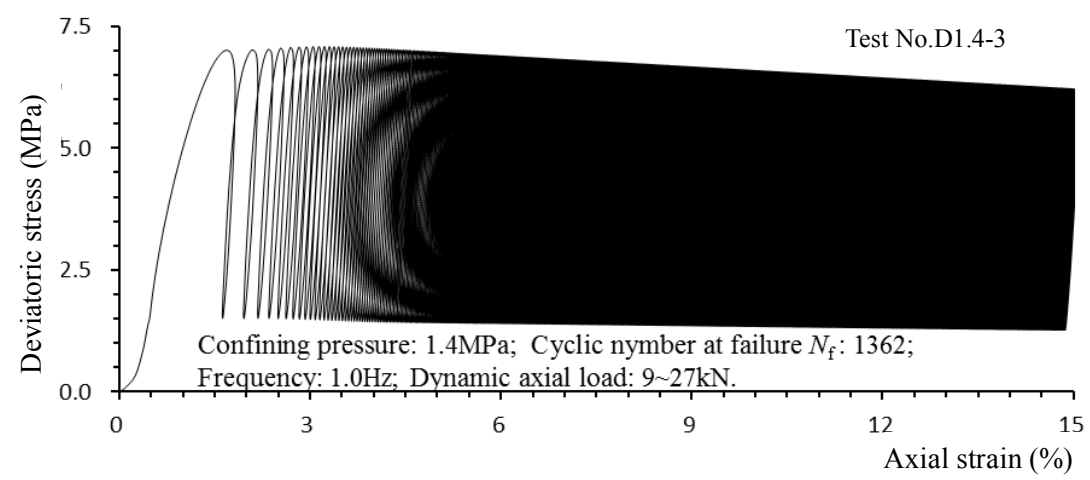

(a) Dynamic deviatoric stress-axial strain curve

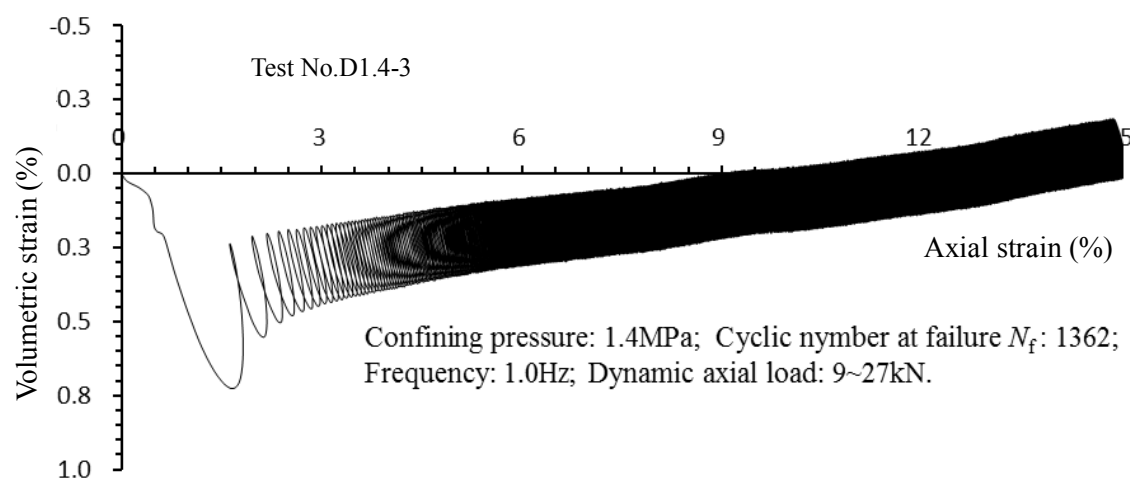

(b) Dynamic volumetric strain-axial strain curve

Fig. 8. Results of triaxial tests upon axial cyclic dynamic loading (D1.4-3) 


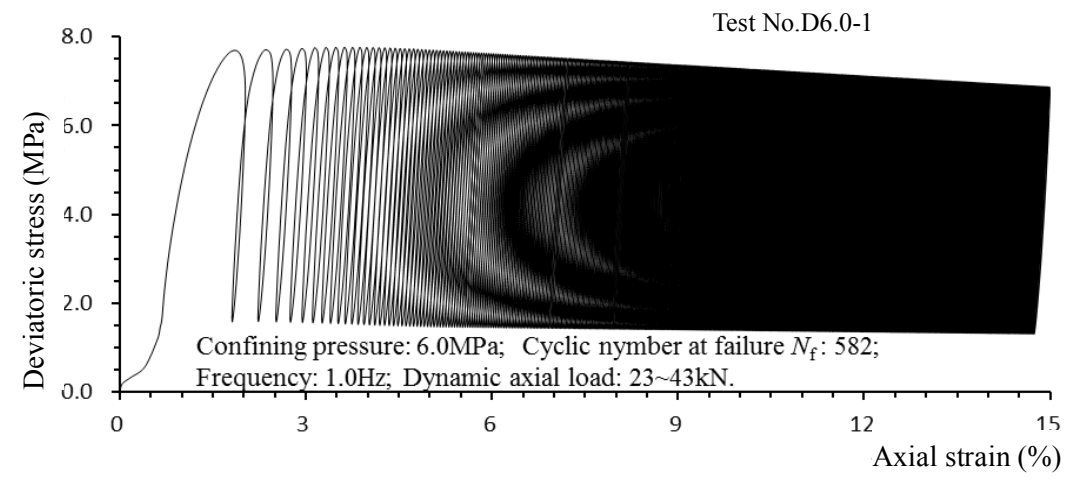

(a) Dynamic deviatoric stress-axial strain curve

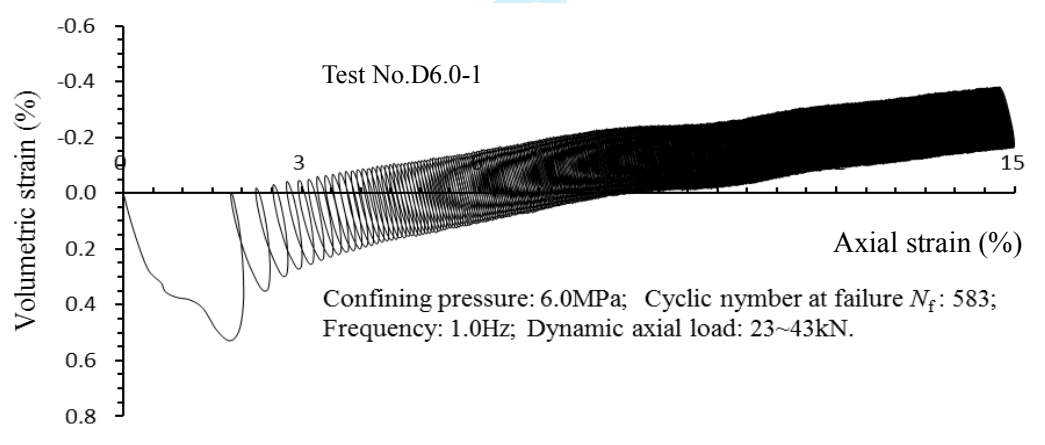

(b) Dynamic volumetric strain-axial strain curve

Fig. 9. Results of triaxial tests upon axial cyclic dynamic loading (D6.0-1) 


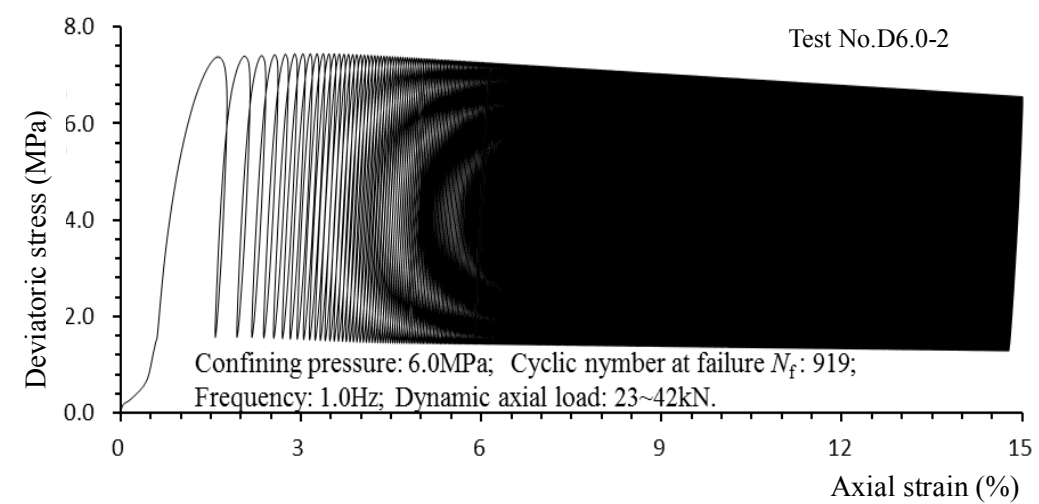

(a) Dynamic deviatoric stress-axial strain curve

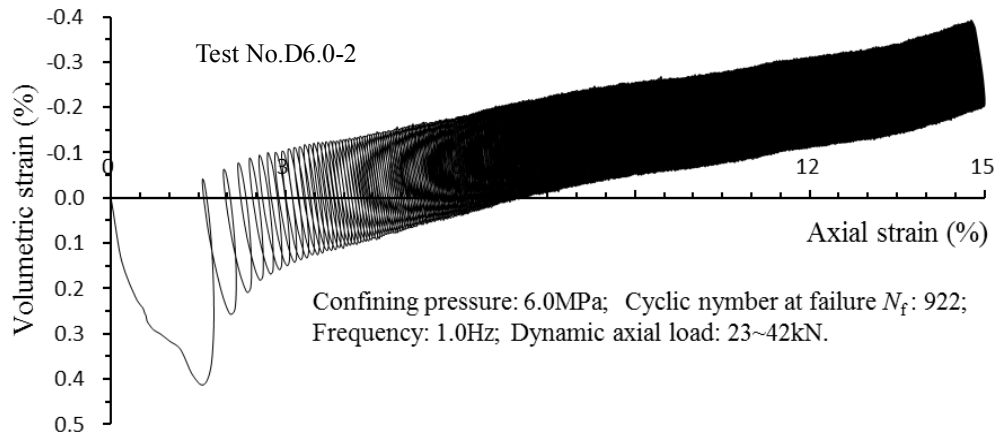

(b) Dynamic volumetric strain-axial strain curve

Fig. 10. Results of triaxial tests upon axial cyclic dynamic loading (D6.0-2) 


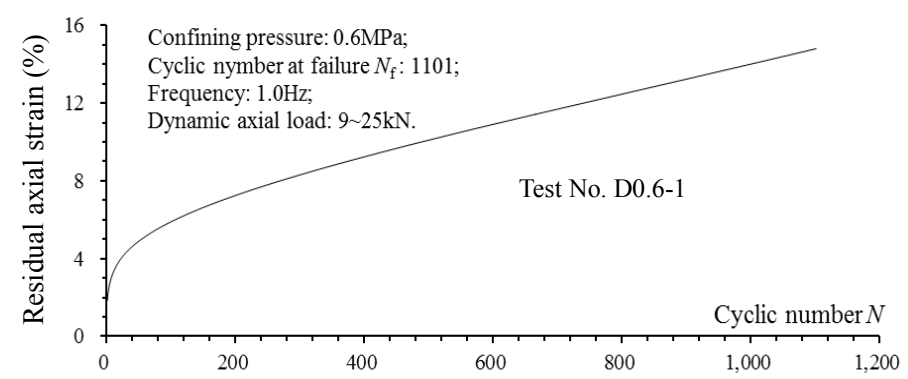

(a) Test No. D0.6-1

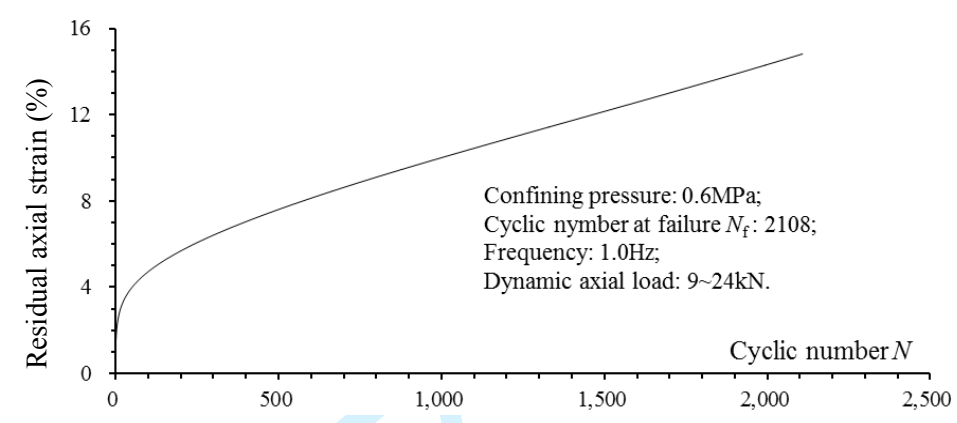

(b) Test No. D0.6-2

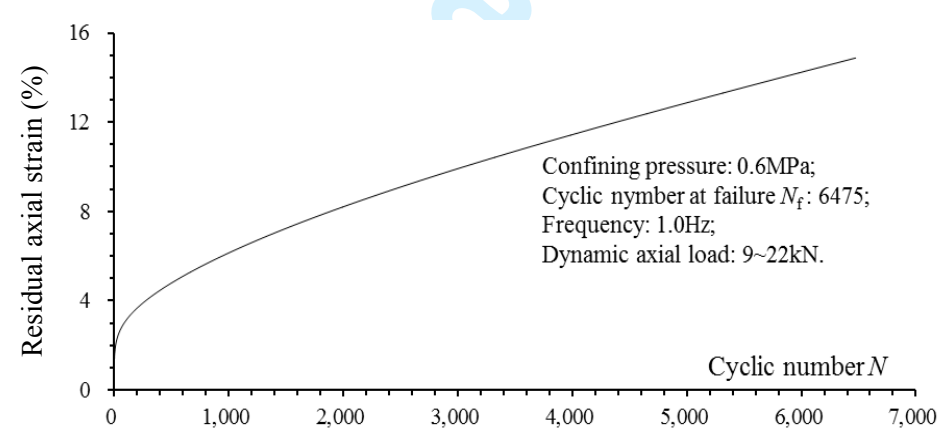

(c) Test No. D0.6-3

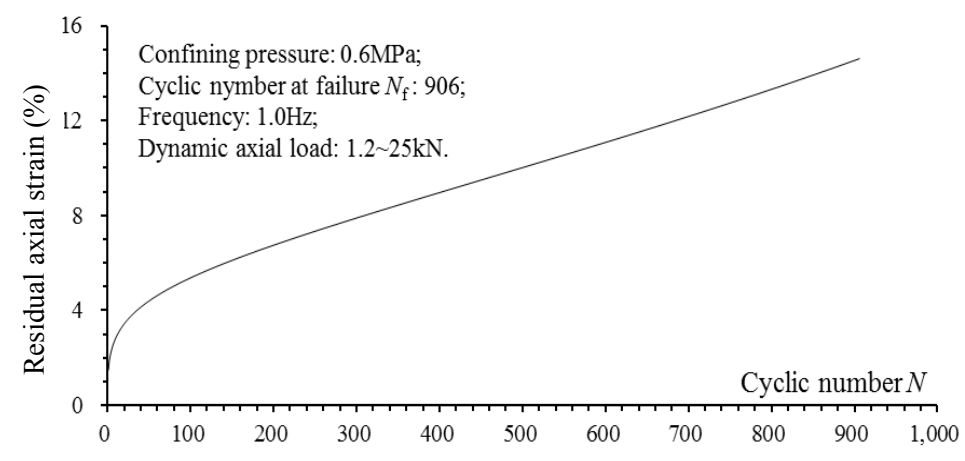

(d) Test No. D0.6-4 


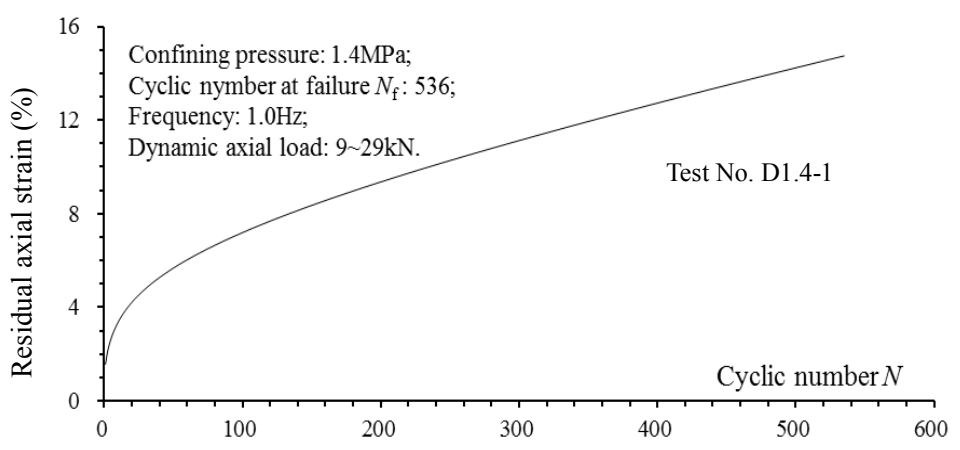

(e) Test No. D1.4-1
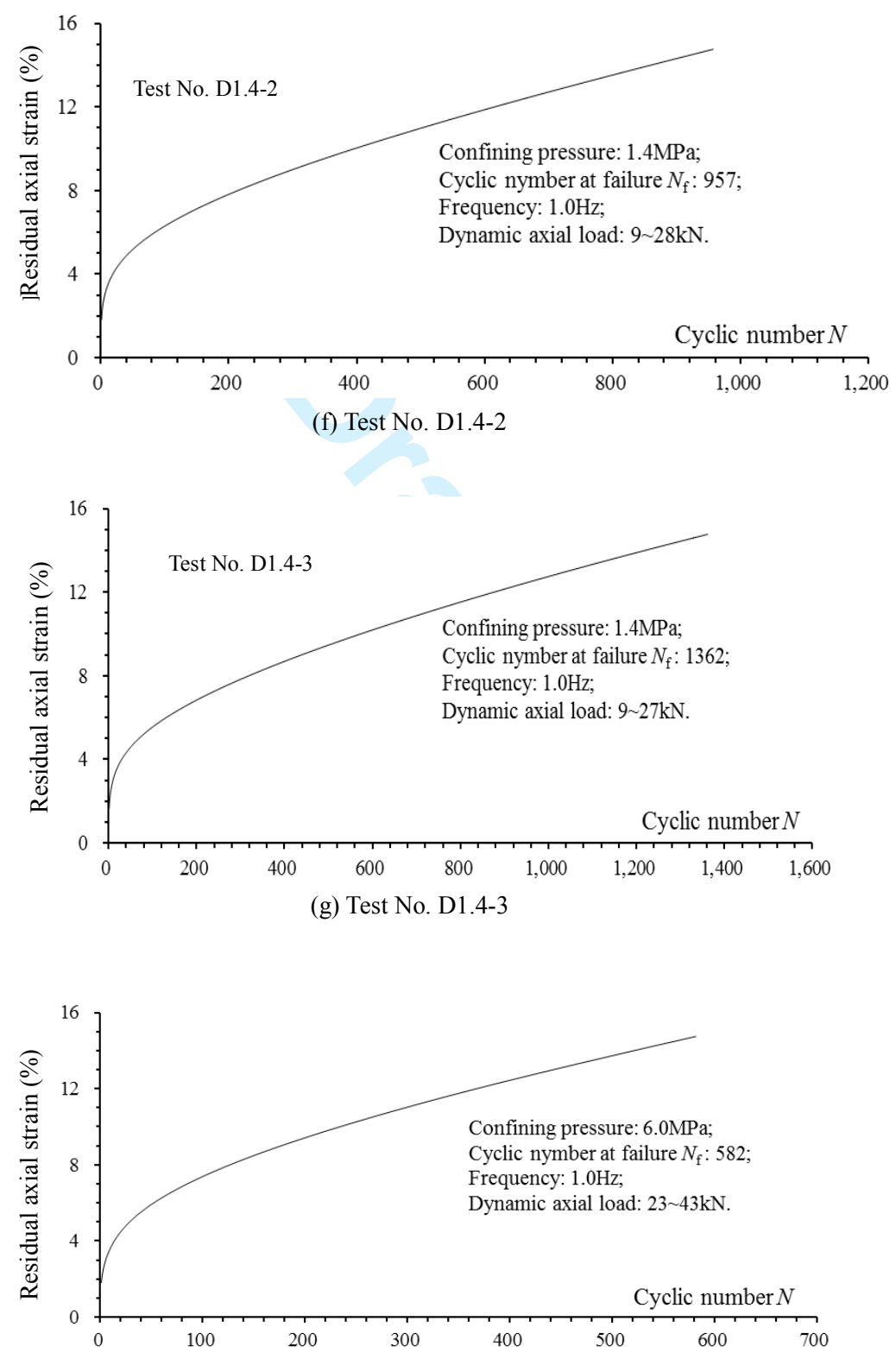

(h) Test No. D6.0-1 


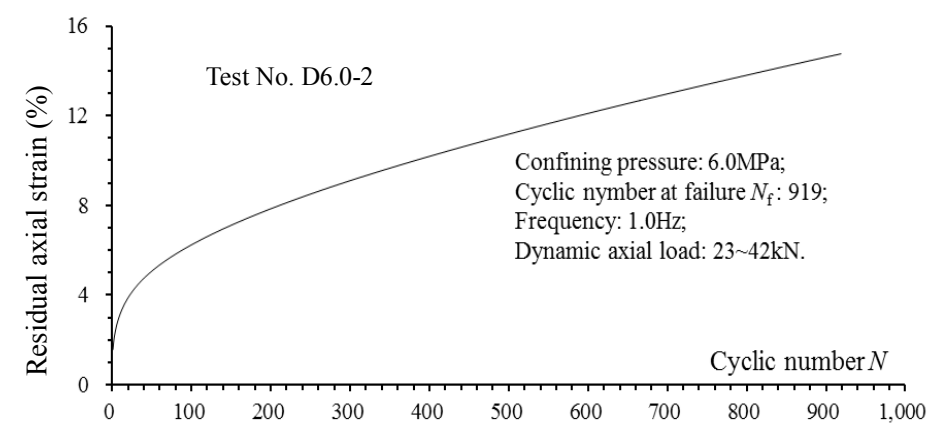

(i) Test No. D6.0-2

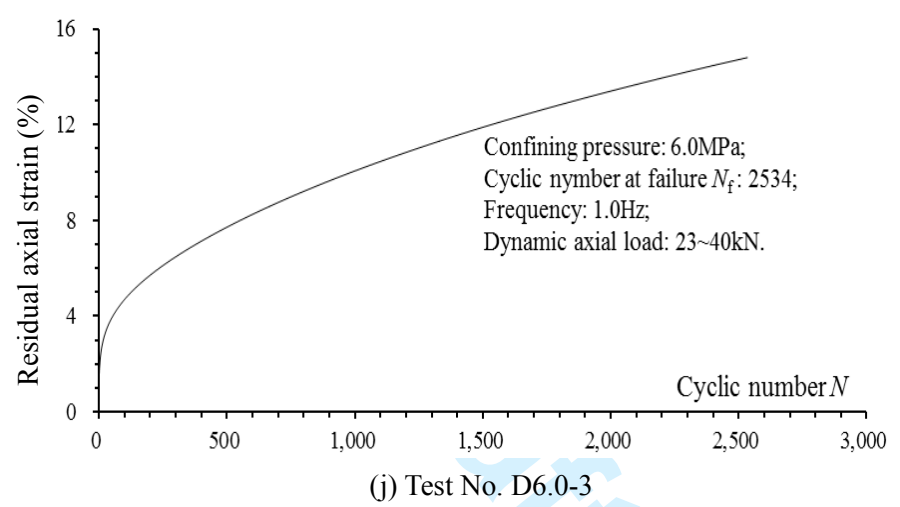

Fig. 11. Residual axial strain- $N$ curves ( $N$ : the number of cycles) 


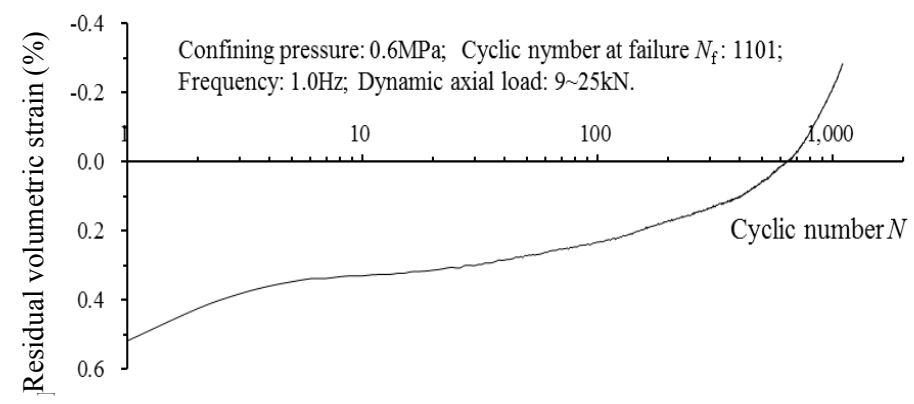

(a) Test No. D0.6-1

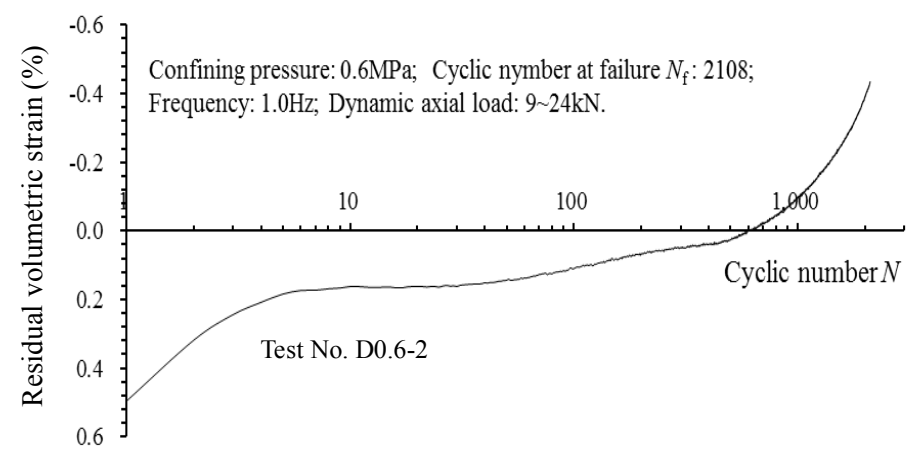

(b) Test No. D0.6-2

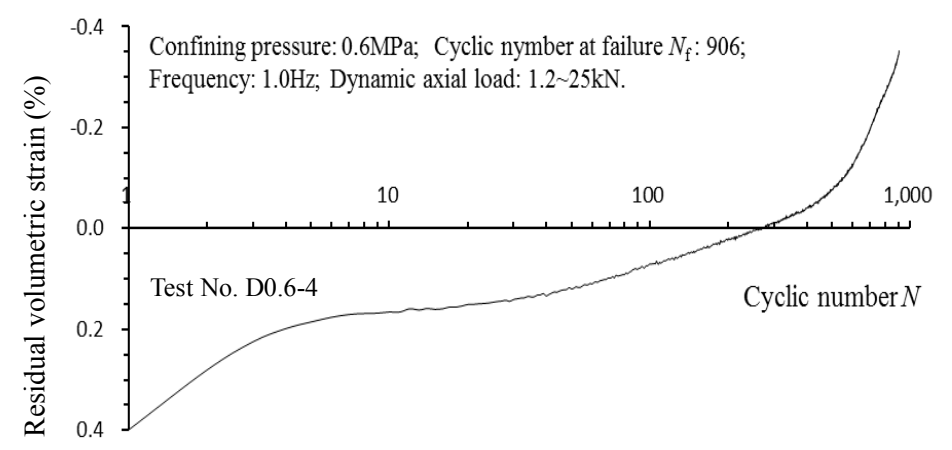

(c) Test No. D0.6-4 


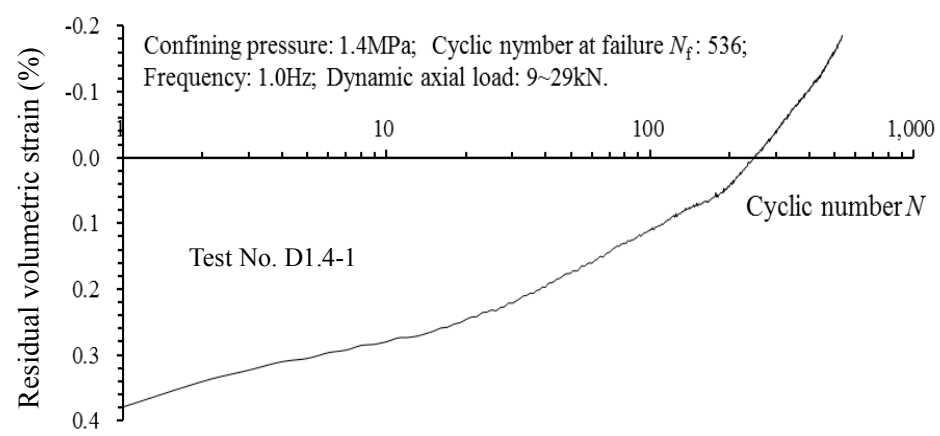

(d) Test No. D1.4-1

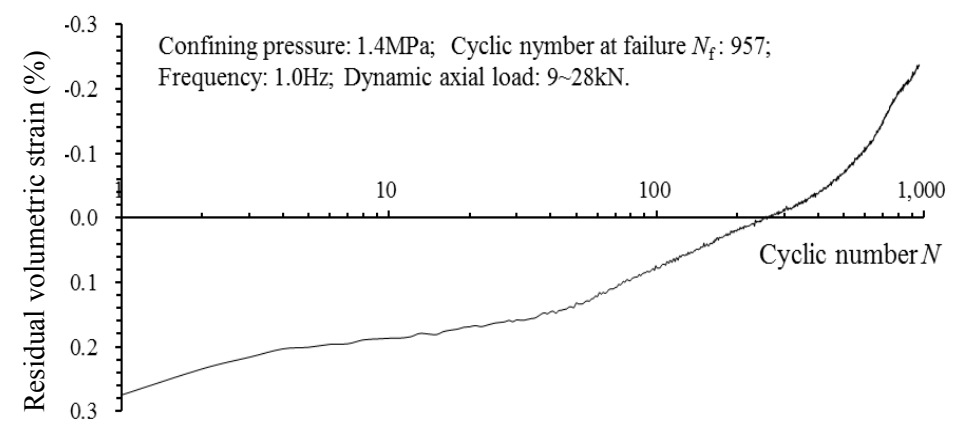

(e) Test No. D1.4-2

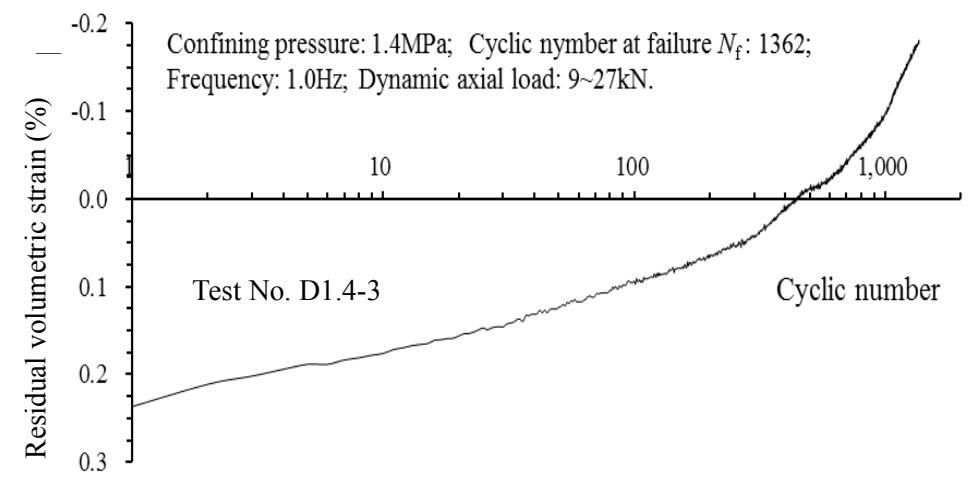

(f) Test No. D1.4-3 


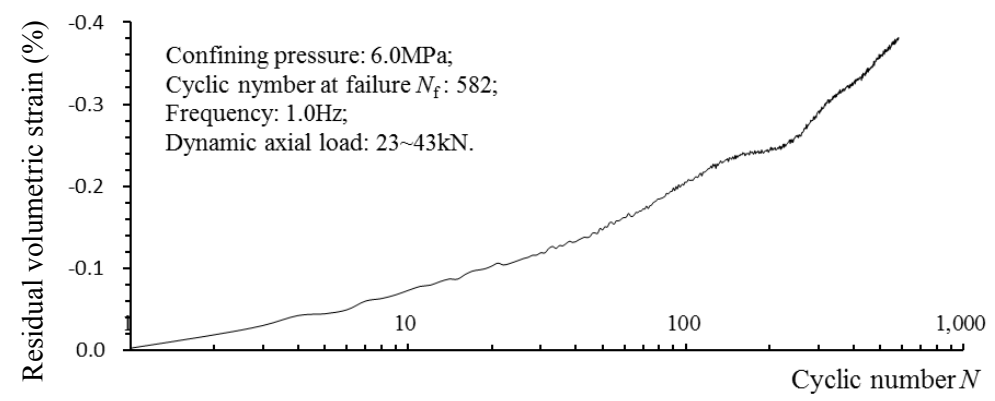

(g) Test No. D6.0-1

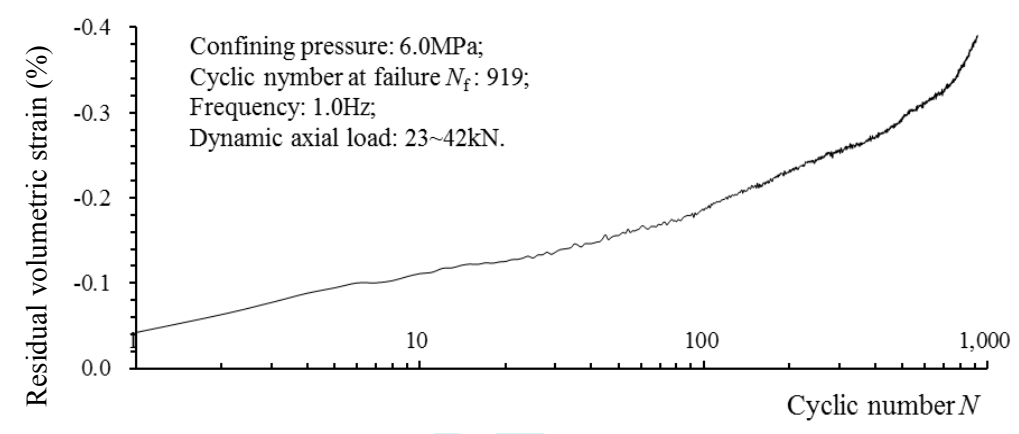

(h) Test No. D6.0-2

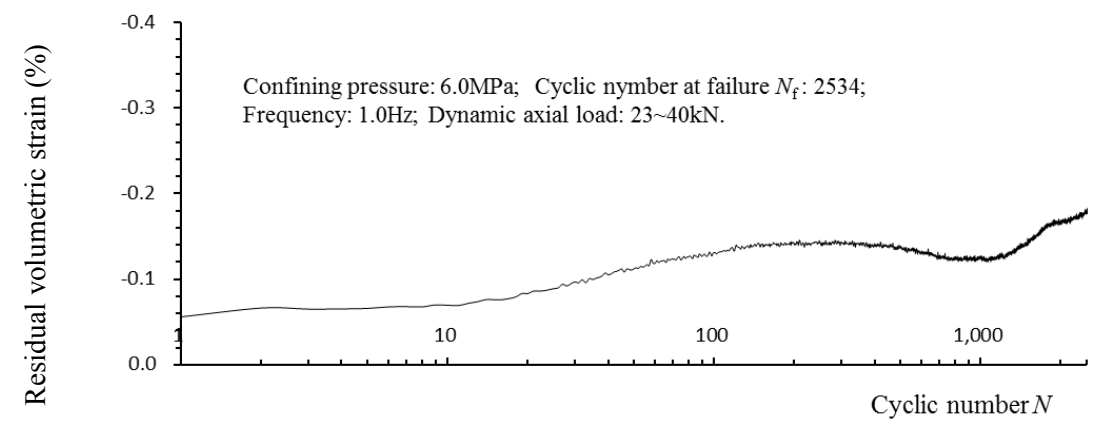

(i) Test No. D6.0-3

Fig. 12. Residual volumetric strain- $N$ curves ( $N$ : the number of cycles) 


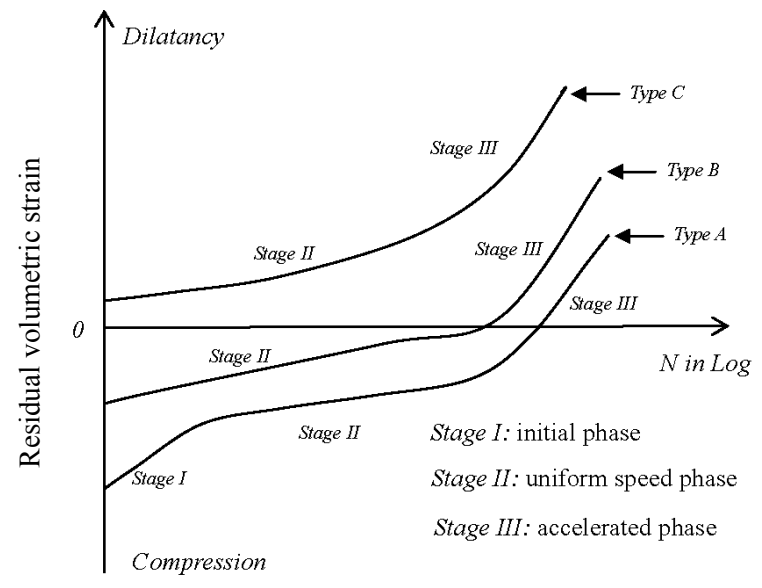

Fig. 13. Plot showing the three phases of residual volumetric strain ( $N$ : the number of cycles) 


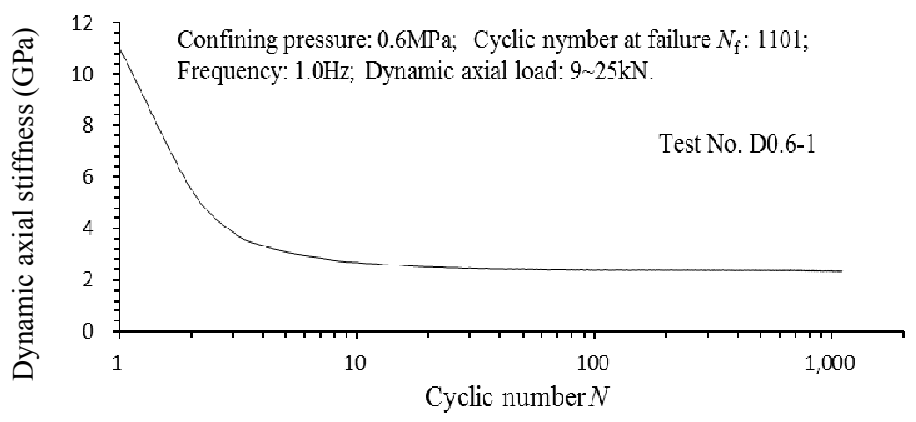

(a) $0.6 \mathrm{MPa}$ confining pressure

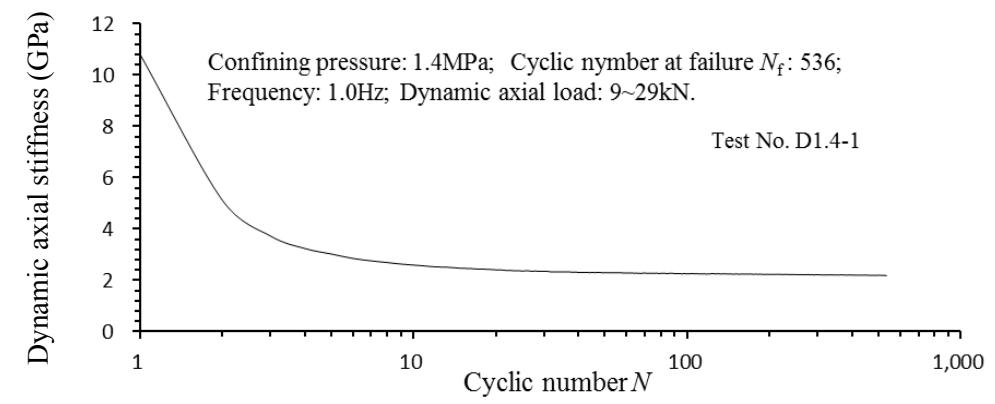

(b) $1.4 \mathrm{MPa}$ confining pressure

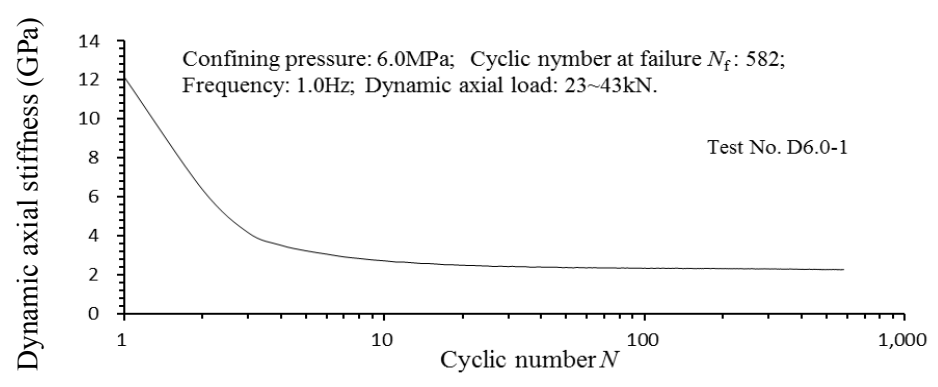

(c) 6.0 MPa confining pressure

Fig. 14. Dynamic axial stiffness- Cycle Number $N$ curve 


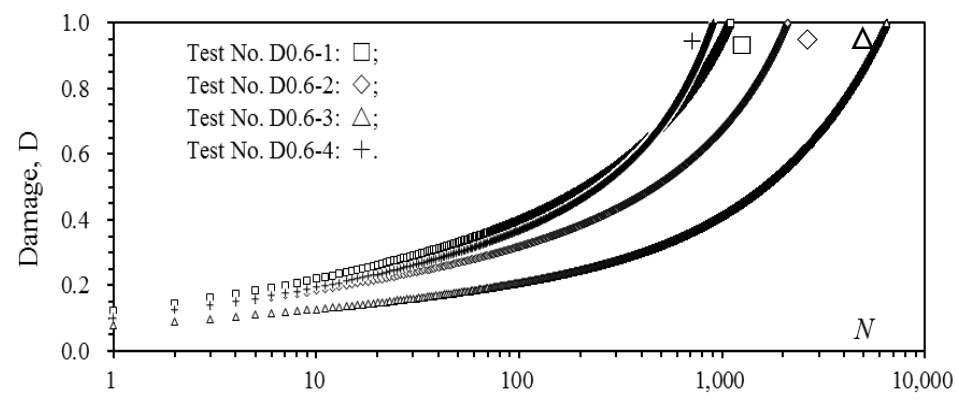

(a) 0.6 MPa confining pressure

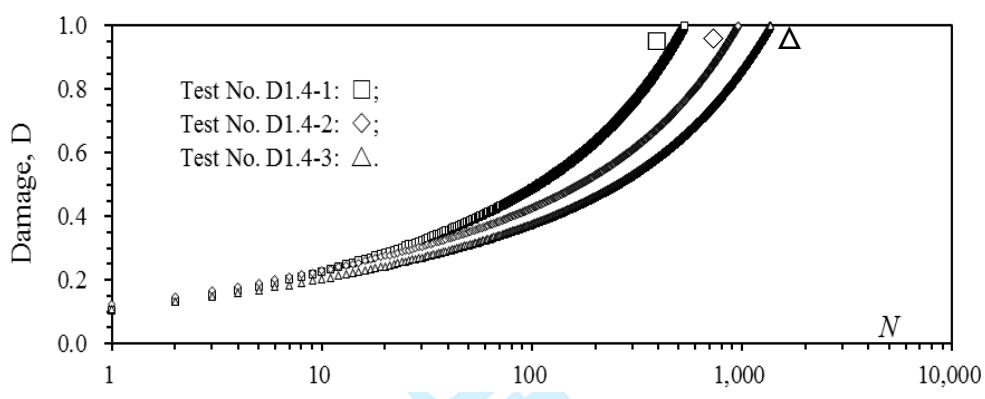

(b) 1.4 MPa confining pressure

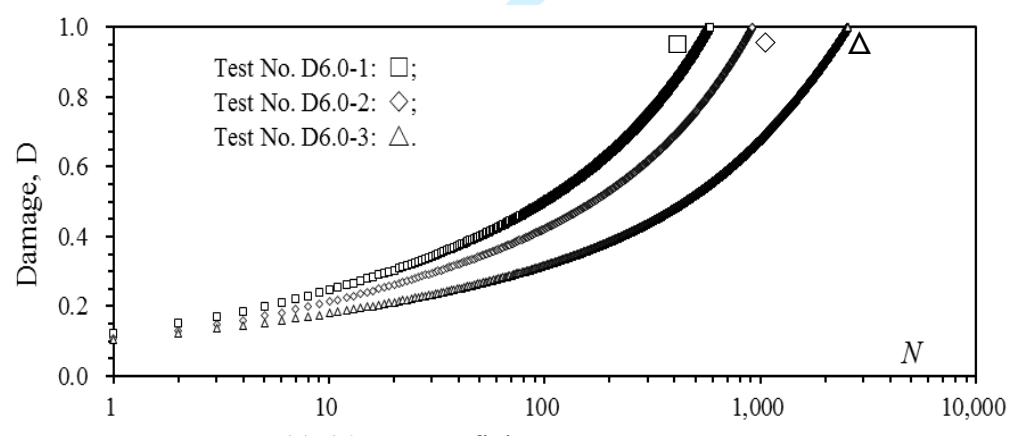

(c) 6.0 MPa confining pressure

Fig. 15. $D$ - $N$ curves ( $N$ : the number of cycles) using the residual axial strain method 


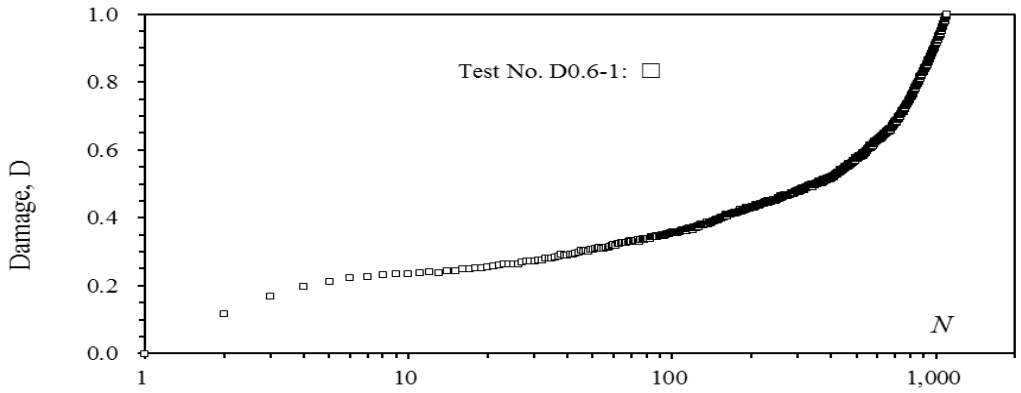

(a)Test No. D0.6-1

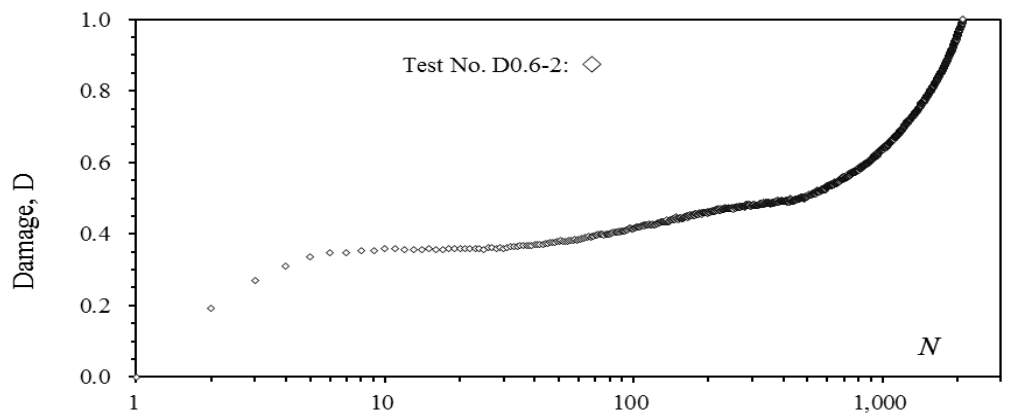

(b)Test No. D0.6-2

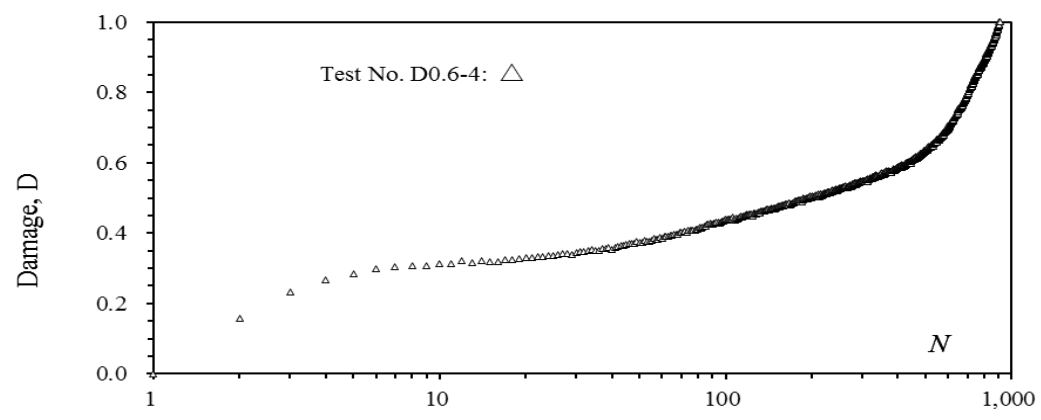

(c) Test No. D0.6-4

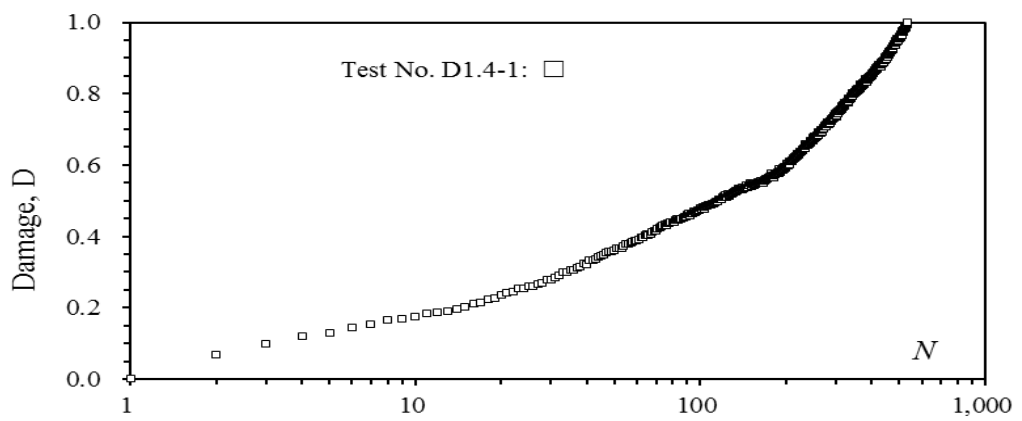

(d) Test No. D1.4-1 


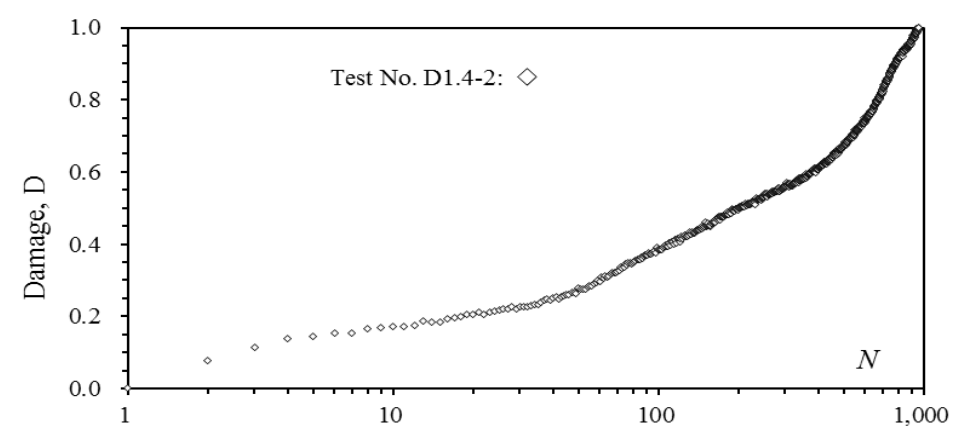

(e) Test No. D1.4-2

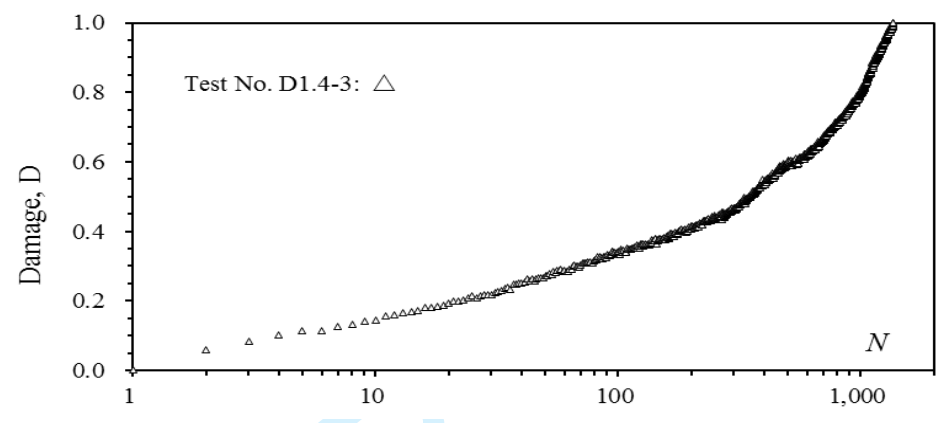

(f) Test No. D1.4-3

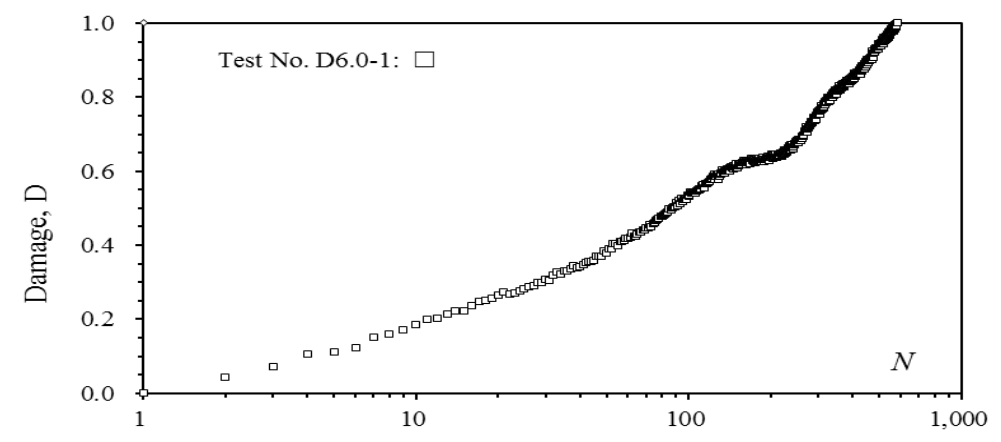

(g) Test No. D6.0-1

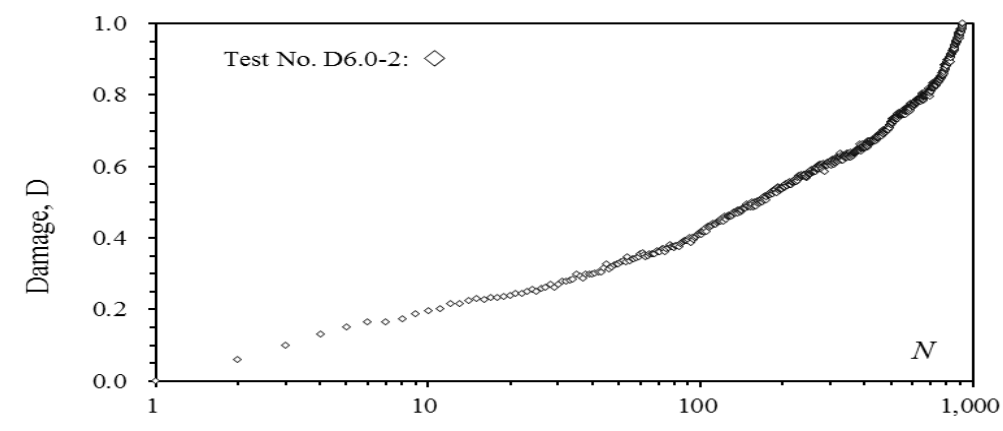

(h) Test No. D6.0-2

Fig.16. $D-N$ curves ( $N$ : the number of cycles) using the residual volumetric strain method 


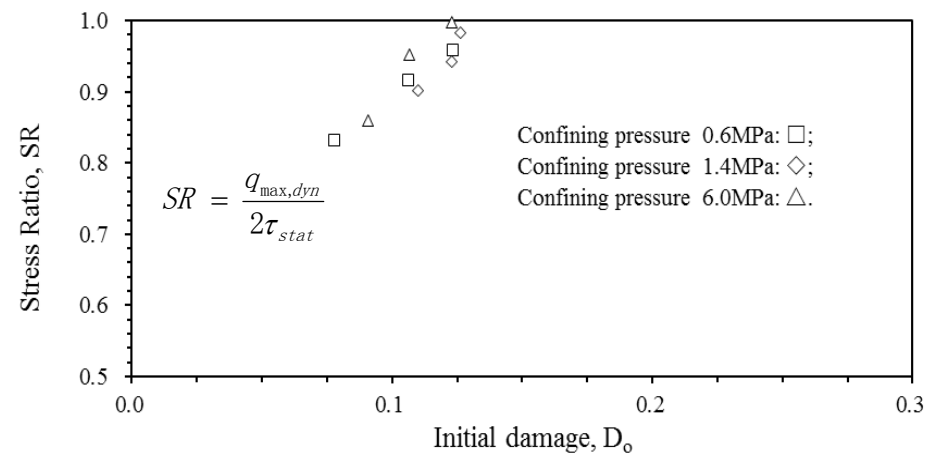

(a) Curves of SR versus $D_{\mathrm{o}}$

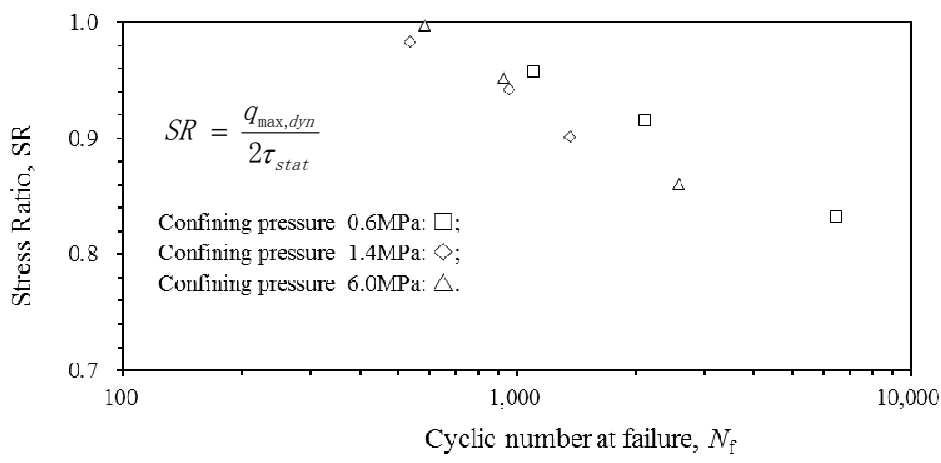

(b) Curves of SR versus $N_{\mathrm{f}}$

Fig. 17. Influence of SR on initial fatigue damage $D_{\mathrm{o}}$ and cycle number at failure $N_{\mathrm{f}}$ 